\title{
Performance-Vesting Provisions in Executive Compensation
}

\author{
J. Carr Bettis ${ }^{\mathrm{a}}$ \\ Arizona State University, Incentive Lab \\ John Bizjak \\ Texas Christian University \\ Jeffrey Coles, ${ }^{\mathrm{c}, *}$ \\ Arizona State University \\ Swaminathan Kalpathy ${ }^{\mathrm{d}}$ \\ Texas Christian University
}

\begin{abstract}
Over the last decade performance vesting (p-v) equity awards have displaced time vesting equity awards. By $201270 \%$ of large US companies granted one or more p-v awards. Based on new methods we develop and implement, we find that p-v provisions significantly amplify executive incentive alignment with shareholder interests (delta) and executive incentives to take risk (vega). Conventional measures of value, delta and vega reflect significant error. These awards are more likely to be adopted for a new CEO and more complex firms. Award usage is associated with a significant subsequent increase in stock performance, accounting performance, and firm risk
\end{abstract}

JEL Classifications: M52, M55, J33, G34; G32, G13, M41.

Keywords: Performance-vesting provisions, executive compensation, stock awards, option awards, timevesting, performance measures, CEO pay, corporate governance.

${ }^{a}$ W.P. Carey School of Business, Arizona State University, Tempe, AZ, 85287, USA; carr@asu.edu

${ }^{b}$ Neeley School of Business, Texas Christian University, Fort Worth, TX, 76129, USA; j.bizjak@tcu.edu

${ }^{c}$ W.P. Carey School of Business, Arizona State University, Tempe, AZ, 85287, USA; jeffrey.coles@asu.edu

${ }^{d}$ Neeley School of Business, Texas Christian University, Fort Worth, TX, 76129, USA; s.kalpathy@tcu.edu

* Corresponding author.

We thank discussants Shane Johnson (2012 Lone Star Finance Conference), Stuart Gillan (9 ${ }^{\text {th }}$ Annual Conference on Corporate Finance, Washington University in St. Louis, 2012), David Erkens (23 ${ }^{\text {rd }}$ Annual Conference on Financial Economics and Accounting, USC, 2012), Lixiong Guo (2013 FIRS Conference), Dalida Kadyrzhanova (2013 SFS Cavalcade), seminar participants at those conferences and at Arizona State University, Chinese University of Hong Kong, TCU, University of Tennessee, and the University of Louisville for helpful comments. The authors are grateful to Incentive Lab, a Scottsdale, Arizona compensation data and science firm, for generously supporting collection of data on vesting provisions and for providing additional data. The analysis and conclusions in this paper are those of the authors and have been formulated independently of the views of Incentive Lab. 


\section{Introduction}

In contrast to traditional time-based vesting, performance-vesting (p-v) provisions either accelerate or trigger vesting of stock, option and cash grants to executives. The criteria for number of units vested or accelerated are based on one or more accounting, stock-price, and other hurdles, such as market share, sales growth, or customer satisfaction. A recent illustrative form of conditional p-v grant conveys stock, with the number of shares granted equal to zero up to some performance threshold, a discrete jump in shares granted at that minimum performance level, and a ceiling number of shares granted beyond a maximal performance level. In between the threshold and ceiling, a range which contains a "target" number of shares granted at a corresponding "target" performance level, is a piecewise-linear schedule, continuous in some instances, with discrete steps in others, specifying how the number of shares granted increases in the performance measure. Figures 1 and 2 depict two such grants of p-v shares. L3 Communications granted stock to CEO Michael Strianese in 2008 contingent on and largely concave in diluted EPS growth rate (Figure 1). Also in 2008, Amgen granted shares to CEO Kevin Sharer, with the number of shares contingent on annualized scaled total stock return (TSR) over a three-year performance period (Figure 2).

To our knowledge, initial usage of this innovation in compensation contracts appeared in the early to mid-1990s in FTSE-100 firms (Camara and Henderson, 2009). ${ }^{1}$ Large U.S.-listed firms followed soon after. Gerakos, Ittner, and Larcker (GIL, 2007) find 128 U.S. firms that between 1993 and 2002 either issued premium options (exercise price above the issue-date stock price) or made a first p-v option grant to their CEOs. Bettis, Bizjak, Coles, and Kalpathy (2010, BBCK) identify 983

\footnotetext{
${ }^{1}$ Camara and Henderson (2009) examine the "real earnings performance based stock option," or the "REPBSO." Carter, Ittner, and Zechman (2009) stress that "the vast majority of long term incentive plans in large UK companies link the vesting of stock options to performance targets, [and one of the] most common performance targets is earnings per share (EPS)". Likewise, Kuang (2008) notes that by 2003, 90 percent of the FTSE top 250 non-financial firms had stock options with performance criteria, and that the most widely adopted target was the growth rate of EPS. Conyon et al (2000) find 72\% of firms in their 1997 sample of UK firms use performance criteria, typically a hurdle based on earnings per share.
} 
p-v grants of stock or options among approximately 2,000 large U.S. firms over the period 19952001. As we build on this prior literature, it is important to note that, in practice, relative to the data and analysis in GIL (2007) and BBCK (2010), the nature of equity-based compensation has changed significantly in two respects. First, early U.S. versions of p-v grants tend to be quite simple, all-ornone in nature, with zero vesting of shares or options up to some threshold level of performance and full vesting of the shares or options if that threshold were met or exceeded. In stark contrast, as we document, among large U.S. firms over the last decade p-v awards of stock, options, and cash to executives are considerably more complex. Second, even in the largest of the early samples p-v provisions represent only about $7 \%$ of stock and option grants, while traditional time-vesting (t-v) grants then were far and away the dominant vesting model. Current practice is substantially different. In U.S. firms, p-v grants are approaching and appear likely to overtake t-v provisions in usage.

This trend to $\mathrm{p}-\mathrm{v}$ provisions is placed in the context of broad-based, visible debate over corporate governance and regulation, ${ }^{2}$ in general, and over the level, structure, and incentive properties of executive compensation, in particular. ${ }^{3}$ Of particular importance is ASC 718 (formerly FAS 123R), which specifies reporting conventions that eliminate prior special treatment for option grants. FAS 123R went into effect in 2005 for most firms. One result appears to have been a significant shift away from option awards towards stock grants (Frydman and Jenter, 2010). Hayes,

\footnotetext{
${ }^{2}$ Various rules arising from the Sarbanes-Oxley Act of 2002 (SOX), the Emergency Economic Stabilization Act of 2008 (EESA), the American Recovery and Reinvestment Act of 2009 (ARRA), and the Dodd-Frank Wall Street Reform and Consumer Protection Act of 2010 ("Dodd-Frank") regulate executive compensation. Moreover, significant latitude was allowed the Special Master for TARP Executive Pay in regulating internal incentives at individual financial firms receiving U.S. government assistance.

${ }^{3}$ In parallel, the recent academic literature focuses significant attention on a wide variety of questions related to executive compensation of interest to regulators and investors. Examples include usage and form of clawback provisions (Chen, Greene, and Owers, 2012; Babenko, Bennett, Bizjak, and Coles, 2012), the effects of incentive alignment on performance (e.g., Coles, Lemmon, and Meschke, 2012), the relation between firm size and pay (Edmans, Gabaix, and Landier, 2009), the relation between pay and domicile (Fernandez, Ferreira, Matos, and Murphy, 2013), whether executives undo pay-related incentives through hedging (Bettis, Bizjak, and Kalpathy, 2011), peer-group formation (Bizjak, Lemmon, and Nguyen, 2011), the effects of compensation structure on risk-taking (Coles, Daniel, and Naveen, 2006), and whether executive pay caused the financial crisis (Murphy and Jensen, 2011).
} 
Lemmon, and Qiu, (2012, HLQ) document the same trend and also provide evidence that firm risk has not declined, a result which appears to be inconsistent with prior evidence (e.g., Coles, Daniel, and Naveen, 2006) that convexity in compensation gives executives the incentive to implement risky policy choices.

In light of the continuing focus on executive compensation, the decline in option grants and the increased usage and complexity of p-v provisions immediately raise at least two issues. First, understanding the value and incentive properties of executive compensation is muddled considerably by the displacement of traditional time-based vesting provisions by complex performance-vesting provisions. To clarify, by value we mean the grant-date or subsequent value of the various components of pay, including short-term and long-term cash awards and grants of stock and options. By incentive characteristics, we mean: "delta," the sensitivity of expected executive wealth to stock price, arising from the stock and option portfolio of the executive; and "vega," the sensitivity of expected executive wealth to a change in the volatility of stock price, arising from the executive's portfolio. ${ }^{4}$ While there has been significant debate over accounting treatment, it is not particularly difficult to value simple time-vested stock and options, or even primitive p-v grants (BBCK, 2010), and to calculate their delta and vega. On the other hand, as we show, value, delta, and vega are significantly more difficult to measure once the grant relies on a complex vesting provision with one or more of an accounting, stock-price, sales, market-share, or other hurdle. One manifestation of the use of byzantine $\mathrm{p}-\mathrm{v}$ features is that in valuing a stock or option grant compensation consultants often apply a simple approximating "haircut” to any p-v grant but, in the authors' experience, without regard for consequential characteristics of the p-v provision. Given the attention that executive compensation receives, particularly the level of pay as reported in accounting statements

\footnotetext{
${ }^{4}$ Delta represents the incentive for executives to increase shareholder wealth (Holmstrom, 1979; Jensen and Murphy, 1990). Vega represents the incentive for executives to take risks (Guay, 1999; Coles, Daniel, and Naveen, 2006).
} 
and elsewhere, better measurement is essential. All parties to the formation of pay in practice have a fundamental need for the facts.

Second, and in the same vein, there can be no useful basis for scientific, policy, or regulatory discussion of executive compensation if the facts concerning value and incentive characteristics are unknown. To be more specific, solving the measurement problem is a necessary condition for assessing whether the level and incentive properties of executive pay are appropriate, vary in the cross-section according to hypothesized economic factors, or affect firm value and risk.

In this context, our paper pursues four differentiating research thrusts. From Incentive Lab we obtain hand collected data from proxy statements on all short-term and long-term grants of stock and options to top executives in 1,833 large U.S. firms over the period 1998-2012. The data facilitate a comprehensive characterization of the incidence and form of both performance-vesting and traditional time-vesting provisions in large U.S.-listed companies. As it turns out, the GIL (2007) and BBCK (2010) samples are only the tip of the growing iceberg. Over 1995-2001, about one in 14 stock and option grants employed a p-v provision (BBCK, 2010). In our sample, as depicted in Figure 4, usage has increased to the point that in 2012 just under $70 \%$ of large U.S. firms utilize in a given year a p-v provision in a grant to one or more executives.

Second, we characterize ex post pay as a function of performance. In particular, enabled in part by enhanced reporting requirements imposed in 2006, we quantify the ex ante grant-date expected value, delta, and vega of executive compensation in the presence of the complex p-v provisions used in practice. Generating these results requires surmounting two difficulties. One arises because it is difficult and expensive to construct a risk-free hedge for $\mathrm{p}-\mathrm{v}$ stock and option grants, so risk neutral valuation methods are inappropriate. We develop a risk-adjusted approach that accommodates both option and stock grants with $\mathrm{p}-\mathrm{v}$ provisions based on accounting or/and 
stock price hurdles. Having solved the valuation problem, when a p-v grant depends on accounting performance and stock and accounting performance are related, conventional delta and vega are incomplete because they neglect the effects of performance and volatility on grant value through the accounting metric channel. Thus, we develop new measures of delta and vega that isolate the marginal effects of accounting performance and volatility and also construct aggregate delta and vega that combine the performance and risk effects through both the stock price and accounting channels. These methodological solutions are particularly relevant given the trends in practice away from time-based vesting towards conditional vesting and towards the use of accounting hurdles in conjunction with or instead of stock price hurdles.

Our simulations predict that the vesting threshold (target, ceiling) will be surmounted about $44(40,36)$ percent of the time, as compared to the actual hit rate at the end of the performance period of $47(41,39)$ percent. Accommodating correlation between the accounting performance metric and stock price and the relation between the grant schedule and the value of the back-end instrument, the grant date value of the typical grant (\$1.11 million) is on average 39\% lower than if the option or stock grant were unencumbered by the p-v provision ( $\$ 1.84$ million). Both value calculations differ from what firms disclose. ASC 718 (2005) requires disclosure of fair value of the award, with the calculation based on variation of the stock price using standard proven methods (e.g., Black-Scholes, binomial lattice models, or Monte Carlo simulations), when the p-v awards depends only on stock price. The requirements for disclosure when the p-v provision depends wholly or in part on an earnings hurdle or other non-price criteria are much more flexible. ${ }^{5}$ In this context, for p-v grants based on a single accounting metric, since 2006 on average firms disclose a value $(\$ 1,112,330)$ that is $19 \%$ higher than the value we calculate $(\$ 934,703)$. In contrast, for $\mathrm{p}-\mathrm{v}$

\footnotetext{
${ }^{5}$ We discuss how valuations are determined and reported under ACS 718 (formerly FAS 123R) in further detail below.
} 
grants based on stock price, on average firms underreport value by $20 \%(\$ 1,584,074$ versus $\$ 1,980,617)$.

We find that $\mathrm{p}-\mathrm{v}$ provisions have significant implications for managerial incentives. Scaling the size of the $\mathrm{p}-\mathrm{v}$ grant to be equal in value to the grant of stock or options had there been no $\mathrm{p}-\mathrm{v}$ provision, marginal stock return delta is approximately 33\% larger on average, while mean aggregate delta is $75 \%$ larger. Average aggregate vega is $474 \%$ larger than it would be if measured without regard for the p-v provision, while aggregate vega of a value-neutral p-v grant is nearly 22 times that of the comparable non-p-v grant. Our analysis indicates that $\mathrm{p}-\mathrm{v}$ provisions significantly amplify the incentives of executives to advance shareholder interests and take risk, effects that are likely to imply substantial consequences for firm performance, risk, investment policy, and financial policy. While option usage has declined since 2006, our analysis indicates that compensation convexity has not, which explains the lack of decline in firm risk-taking that is purported by HLQ (2012) to be a puzzle.

Third, enabled by our panel data, we characterize and seek to explain cross-sectional and time-series usage patterns of $\mathrm{p}-\mathrm{v}$ provisions and isolate the causes and consequences of changing usage patterns. We find that the propensity to use a $\mathrm{p}-\mathrm{v}$ provision is strongly related to implementation of accounting changes in 2005. As stock is displacing options as the back-end security, performance vesting is displacing time vesting. If a firm wants the CEO to implement risky policy by conveying vega to the CEO (per Coles, Daniel, and Naveen, 2006), it is possible to do so even with a stock grant so long as the award uses a p-v provision. The data are strongly consistent with this hypothesis. For a given firm, increased usage of p-v stock is significantly positively related to decreased usage of $\mathrm{t}-\mathrm{v}$ options and this effect is much more pronounced after 2005. Furthermore, usage of performance vesting rather than time vesting is positively related to the use of a 
compensation consultant, whether the compensation consultant has significant market share, CEO turnover, firm size, number of business segments, $\mathrm{p}-\mathrm{v}$ usage in the industry, board size, board independence, and board interlocks. P-v usage is negatively associated with volatility of firm stock return and CEO ownership. The results on firm size are consistent with economies of scale in sophistication of contract design. Moreover, it appears that firm complexity, measured by firm size, and compensation complexity are positively related. The results on compensation consultants are consistent with the notion that consultants either assist in contractual innovation to increase firm value or vend complexity that increases their rents. Our result on CEO turnover is consistent with the evidence in BBCK (2010). Their interpretation is that p-v provisions can be a way for the firm to avoid conveying stock or options to a departing CEO who has been discovered (e.g., from poor firm performance) to be a poor match for the firm (see BBCK, 2010), an effect that is increasingly important given that the rate of CEO turnover is increasing through time (Kaplan and Minton, 2012). Conditional on use of performance vesting, we find a strong trend towards using accounting and other metrics rather than stock-price triggers. The reason, in part, is likely to arise from ASC 718 (FAS 123R), which allows for more flexible reporting requirements for grants that depend on something other than stock price. ${ }^{6}$

Finally, we document the association between usage of performance vesting and firm risk, performance, and policy. Using a p-v provision is associated with a significant subsequent increase in stock performance, accounting performance (ROA), and firm risk. While these results are striking, our experimental attempts to identify the mechanisms of these changes are not successful. To be specific, there appears to be no associated change in investment policy (R\&D intensity, investment) or financial policy (leverage).

\footnotetext{
${ }^{6}$ An additional reason for the growth of $\mathrm{p}-\mathrm{v}$ awards is the greater role proxy advisors are playing in pay design. Both Glass Lewis and ISS, two of the most prominent proxy advising firms, recommend the adoption of p-v provisions in executive pay.
} 


\section{Definitions and Examples}

Contingent-vesting awards require that one or more performance hurdles be achieved for the grant to vest. Failure to meet the performance conditions results in the forfeiture of the awards. A very simple, all-or-none example would be a grant of $\mathrm{N}$ shares of stock to an executive that would vest only if the stock price increased by Y\% within $\tau$ years. ${ }^{7}$ Such simple grant schedules were the predominant form when US firms began to use p-v provisions (BBCK, 2010).

As Figures 1 and 2 indicate, both L3 Communications and Amgen recently used more complex, but still somewhat simple, contingent vesting provisions. As revealed in the Grants of Plan-Based Awards (GPBA) table, at the threshold, Mr. Kevin Sharer, the CEO of Amgen, would earn 36,500 common shares, at the target he would receive 73,000 shares, and at the ceiling he would receive 146,000 shares. The description of the award specifies interpolation between threshold, target, and ceiling. The executive receives no shares for three-year annualized TSR less than $0 \%$ per year, $50 \%$ of target (36,500 shares is half of target 73,000 shares) at annual TSR of $0 \%$, 73,000 shares at annual TSR of $8 \%$, and three-year annualized TSR of $18 \%$ or greater earns the maximum of 146,000 shares (or $200 \%$ of target). Such details allow full characterization of the ex post functional form of the grant schedule for the stock award.

We find that performance-vesting provisions depend on a wide variety of metrics and in some cases multiple metrics. From the 2008 Brunswick proxy, we have:

With respect to the special 2008 PS award, the number of PSs earned will be based on performance against several key strategic factors by the end of 2010. Those measures and target performance include Sales Per Salaried Employee (7 percent increase versus 2007), Sales Per Capital Employed (3.2) and Return on Capital Employed (11\%). Payout of 50 percent to 125 percent of target award is based solely on performance against performance criteria referenced above. An additional 25 percent

\footnotetext{
${ }^{7}$ See Conoco's 1998 grant of stock options to CEO Archie Dunham for a specific example of a simple conditional p-v provision (Bettis, Bizjak, Coles, and Kalpathy, 2010).
} 
of target award could be earned if stock price exceeds $\$ 25$ and relative total shareholder return versus the S\&P 500 is equal to or greater than the 60th percentile. In addition, there will be a minimum Company stock price threshold of $\$ 20$ per share prior to any award being earned.

This grant of "performance shares" employs several performance metrics. Also note that a portion of the award is defined based on TSR relative to shareholder return of firms in the S\&P 500 . Though absolute awards make up the majority of our sample, relative awards are employed with some regularity. Because of additional complexities of analyzing relative awards, we concentrate instead on absolute p-v awards, which represent the majority in the data over our sample period. ${ }^{8}$

\section{Measuring the Value of P-V Grants}

\subsection{The p-v grant schedule}

Suppose an award employs $I$ performance metrics, $\vec{X}=\left(X^{1}, X^{2}, \ldots, X^{I}\right) .{ }^{9} \quad$ For example, there can be two performance metrics $(I=2), X^{1}=A$ and $X^{2}=P$, where $X_{t}^{1}=A_{t}$ is meant to represent the level of an accounting metric that is the basis for a performance measure (e.g., some measure of earnings, EPS, ROA, ROE, ROI, etc.) or other performance measure (such as sales, market share, FDA approval, etc.) and $X_{t}^{2}=P_{t}$ is stock price of the firm. The subscript indicates time $t$, for $t \geq 0$, for the initial grant date $(\mathrm{t}=0)$ and thereafter. While this example and associated notation are meant to focus on the mix of one accounting metric and one stock-price metric, more generally both $A$ and $P$ can be accounting performance metrics or both can be stock-price metrics. Moreover, the stock performance metric is not always stock price but something instead that is a function of stock price (e.g., total stock return scaled and annualized). Thus, in some instances we

\footnotetext{
${ }^{8}$ See Bettis, Bizjak, Coles, and Young (2013) for evidence on the growing use of RPE awards in executive pay.

${ }^{9}$ As illustrated in the Brunswick example, there can be relative performance evaluation, in which case the performance metrics would be evaluated relative to a vector of benchmarks. Again, because absolute performance evaluation (APE) is employed more often in practice, we concentrate on absolute awards,
} 
specify $X_{t}^{2}=R\left(P_{t}\right)$, where $R($.$) is a function of stock price. Returning to the most general case, as$ seen in practice, there can be more than two performance metrics. The performance vector has initial value at the grant date, $t=0$, denoted $\overrightarrow{X_{0}}=\left(X_{0}^{1}, X_{0}^{2}, \ldots, X_{0}^{I}\right)$. For purposes of determining the number of units of the back-end instrument to be conveyed to the executive, performance is evaluated over some time horizon, the performance period, from $t=0$ to $t=\tau$.

Let the number of units of the back-end instrument, stock or options, that are conveyed to the executive at time $\tau$, the end of the performance period, be given by the grant function, $N\left(\overrightarrow{X_{\tau}}\right)$. In the two-metric example, this grant schedule is written $N\left(\overrightarrow{X_{\tau}}\right)=N\left(A_{\tau}, P_{\tau}\right)$. Grant schedules in practice vary widely in design. Early (1995-2001) conditional p-v grant schedules tended to be single-step functions in one performance metric (BBCK, 2010). More recently, grant schedules have become significantly more complex, such as surfaces over a domain of multiple performance metrics, with the surfaces containing steps and folds. Moreover, the nature of the tradeoff between multiple performance metrics varies across grants.

In the two-metric example, some grants require improvement in both metrics to obtain an increase in the number of units to be granted. Such grants can be written as $N\left(A_{\tau}, P_{\tau}\right)=$ $f\left[\min \left\{A_{\tau} / B, P_{\tau} / Q\right\}\right]$. This grant, call it a "min" or "and" grant, allows no tradeoff between the two performance metrics. $B$ and $Q$ define the location of the vertex of the right-angled level set of the grant function in units as a function of the two performance metrics. A more forgiving grant, an "or" or "max" grant, specifies right-angled level sets of the grant function that oppose the axes of the performance metrics, per $N\left(A_{\tau}, P_{\tau}\right)=g\left[\max \left\{A_{\tau} / B, P_{\tau} / Q\right\}\right]$. Intermediate flexibility in trading off one performance metric versus the other can come in the form of a "linear" grant, with $N\left(A_{\tau}, P_{\tau}\right)=$ $h\left[\left(A_{\tau} / B\right)+\left(P_{\tau} / Q\right)\right]$, for which $B$ and $Q$ define the slope of the linear level set of the grant function. Other grants are "side-by-side," with two functionally independent grants that are linked only 
through correlation of the performance metrics, with $N\left(A_{\tau}, P_{\tau}\right)=v\left(A_{\tau} / B\right)+w\left(P_{\tau} / Q\right) .{ }^{10}$ Our data contain all four of these classes of equity-based grants. In our data the functions $f[],. g[],. h[$.$] ,$ $v($.$) , and w($.$) tend to have steps and kinks, for example at "threshold," "target," and "ceiling."$

\subsection{Value of the back-end instrument after the performance period}

Define the value of the stock, options, or cash conveyed at any time $t \geq \tau$ (at or after the end of the performance period) as $V\left(\overrightarrow{X_{t}}\right)$, or $V\left(A_{t}, P_{t}\right)$ in the simple case. Note that the award itself could be a number of shares or options that vest fully at time $\tau$. Otherwise, shares or options could be restricted by a subsequent time-based or $\mathrm{p}-\mathrm{v}$ schedule, with the relevant performance period beginning at the end of the first performance period.

We are particularly interested in $t=\tau$, the point at which the number of units of the back-end instrument is known. Setting aside for the moment any question of dilution, if the back-end instrument is shares unrestricted by additional time vesting, then $V\left(\overrightarrow{X_{\tau}}\right)=V\left(A_{\tau}, P_{\tau}\right)=P_{\tau}$, the stock price per share at $\tau$. If the back-end instrument is options or stock appreciation rights unrestricted by additional time vesting, and remaining time to maturity is positive, the Black-Scholes option value adjusted for dividends often will be suitable. We denote the Black-Scholes value (or simulated value, if that approach is employed) adjusted for dividends of the single call option as $c\left(P_{t}, K, \sigma_{r}, d\left(\mathrm{~F}_{t}\right), T-t, r_{f}\right)$, where $P_{t}$ is stock price at $t \geq \tau, K$ is exercise price (set at the initial grant date $t=0$ ), $\sigma_{r}$ is the standard deviation of return on the stock, $d\left(\mp_{t}\right)$ is the schedule of $N$ remaining (at time $t$ ) dividend payments as a proportion of stock price to be paid on dates $F_{t}=\left\{t_{1}, t_{2}, \ldots, t_{N}\right\}$ (with $t_{1} \geq t$ and $t_{N} \leq T$ ), remaining time to maturity is $T-t$, and $r_{f}$ is the risk free rate. Of course, if there is no remaining time to maturity, the value of the expiring option is intrinsic value, the difference $P_{T}$ -

\footnotetext{
${ }^{10}$ In some instances, if the functions $v$ and $w$ are linear, for example, a side-by-side grant can be characterized as a linear grant, but more generally it is not possible to characterize a side-by-side grant as linear or vice versa.
} 
$K$. If $T-\tau>0$, then we write $V\left(A_{\tau}, P_{\tau}\right)=V\left(P_{\tau}\right)=c\left(P_{\tau}, K, \sigma_{r}, d\left(\mathrm{~F}_{\tau}\right), T-\tau, r_{f}\right)$. For both options and stock, $V\left(A_{\tau}, P_{\tau}\right)$ depends on $P_{\tau}$ only and not on $A_{\tau}$, so we write $V\left(A_{\tau}, P_{\tau}\right)=V\left(P_{\tau}\right) .{ }^{11,12}$

\subsection{Value of the p-v grant at the end of the performance period}

Ex post value of the conditional $\mathrm{p}-\mathrm{v}$ grant, at the end of the performance period, is the product of the number of units earned through the performance-vesting provision and the value at time $t=\tau$ per unit of the back-end instrument, $N\left(\overrightarrow{X_{\tau}}\right) V\left(\overrightarrow{X_{\tau}}\right)$. In the simple two-metric case with no dependence of the back-end instrument on $A_{\tau}$, ex post value is $N\left(A_{\tau}, P_{\tau}\right) V\left(P_{\tau}\right)$.

In the 2008 Amgen example, the grant schedule is a function of annualized total stock return, including dividends accumulated over the performance period 0 to $\tau$ (div $0 \tau$ ), expressed as a proportion of initial stock price, to be measured at the end of three years $(\tau=3)$. Raw total stock return over the period $t=0$ to $t=3$ is $P_{3}+d i v_{03}-P_{0}$, and scaled annualized $T S R_{03}=\left(1+\left(\left(P_{3}+\right.\right.\right.$ $\left.\left.\left.d i v_{03}-P_{0}\right)\left(P_{0}\right)\right)\right)^{(1 / 3)}-1$. A judgment is required whether to use one performance metric, $X_{\tau}=T S R_{0 \tau}$, or two, $X_{\tau}^{1}=P_{\tau}$ and $X_{\tau}^{2}=d i v_{0 \tau}$. In large part, the decision depends on whether it is appropriate to combine stock price appreciation and dividends when modeling the drift, volatility, and covariances of the state variables. If dividend yield is constant at $d$, then we can use $R_{t}=$ $R\left(P_{t}\right)=P_{t}+d i v_{0 t}=(1+d) P_{t}$, with $P_{0}$ embedded in the grant schedule. If the dividend level is fixed, we can embed $d i v_{0 t}$ in the grant function. $R_{t}=R\left(P_{t}\right)$ accommodates numerous other cases

\footnotetext{
${ }^{11}$ While we concentrate on stock and options, some firms award cash as the back-end instrument, in which case $V\left(A_{\tau}, P_{\tau}\right)=\$ 1$. While we see no evidence of such in the data, it is possible to imagine cash payments or stock or option grants that depend on $A_{t}$. For example, the back-end unit at the end of the performance period could be another p-v grant with the performance-vesting provision contingent on both $A_{t}$ and $P_{t}$ or $A_{t}$ alone.

12 Though the framework accommodates additional complexities, for now herein we make several simplifying assumptions. First, we assume grants of stock and options are unencumbered by time-based vesting restrictions subsequent to the performance period. Second, most option grants are warrants that are dilutive on exercise. Modeling options as warrants does not appear to make a large difference (Anderson and Core, 2013). Thus, we do not adjust value for anticipated dilution. Third, we value the back-end instrument from the point of view of the diversified investor and make no adjustment for incomplete diversification in the portfolio of a risk-averse executive. Fourth, we adjust the value of options to reflect early exercise, but do not model cross-sectional variation in early exercise (Bettis, Bizjak, and Lemmon, 2005). Adjustments for all of the above are feasible, though we do not do so in this analysis so as to reduce the costs of analyzing a large sample of awards.
} 
in practice. For Amgen, we use TSR as the single performance metric and model drift in $P_{t}+d i v_{0 t}$. Figure 2 shows the number of shares, $N\left(X_{\tau}\right)=N\left(T S R_{03}\right)=N\left(R\left(P_{3}+d i v_{03}\right)\right)$ to be received by the CEO based on scaled annualized TSR at the end of the three-year performance period, where $T S R_{0 \tau}=R\left(P_{\tau}+d i v_{0 \tau}\right)$ and $\left.T S R_{03}=R\left(P_{3}+d i v_{03}\right)=\left(1+\left(\left(P_{3}+d i v_{03}-P_{0}\right) / P_{0}\right)\right)\right)^{(1 / 3)}-1$.

Figure 3 depicts the value of the 2008 Amgen stock grant at the end of the performance period in 2011 as a function of stock price at the end of the three-year performance period. In this figure, for visual simplicity we suppose accumulated dividends are zero (or built in to $P_{\tau}$ ). Note that convexity of portions of the graph of ex post value of the stock grant as a function of $P_{\tau}=P_{3}$ arises because of convexity in the grant schedule and also because both the value per unit of the back-end instrument, stock in this case, and the number of shares conveyed both depend on stock price at the end of the performance period. Thus, portions of the ex post value of the stock grant are quadratic in $P_{\tau}=P_{3}$.

\subsection{Evolution of the state variables, $\overrightarrow{X_{t}}$}

A probabilistic model of how the state variables $\overrightarrow{X_{t}}$ evolve from initial values $\overrightarrow{X_{0}}$ over the performance period, $t=0$ to $t=\tau$, and beyond to any other $t>\tau$ of interest, is required. We assume that rate of change in $\overrightarrow{X_{t}}, \overrightarrow{r_{X}}$, has a stationary multivariate cumulative distribution, $\overrightarrow{r_{X}} \sim \mathrm{F}(\vec{\mu}, \Sigma)$, with $I$ x 1 vector of expected values given by $\vec{\mu}$ and the $I$ x $I$ covariance matrix by $\Sigma$. These return parameters determine the drift and volatility of the levels $\overrightarrow{X_{t}}$ per unit time. For illustration, consider the simple two-metric case with state variables $\left(A_{t}, P_{t}\right)$ that evolve according to $\left(r_{A}, r_{P}\right) \sim \mathrm{F}(\vec{\mu}, \Sigma)$, with $\vec{\mu}=\left(\mu_{A}, \mu_{P}\right)$ and $\left\{\sigma_{C D}\right\}_{C, D=A, P}$. The five parameters are drift rate in the accounting measure, drift rate in stock price, volatility in both, and their covariance.

\subsection{Grant date (ex ante) discounted expected value of ex post realized value}


Let $\rho$ be the discount rate applied to $N\left(\overrightarrow{X_{\tau}}\right) V\left(\overrightarrow{X_{\tau}}\right)$, the product of the number of units of the back-end security conveyed times value per unit, both at the end of the performance period. If $N\left(\overrightarrow{X_{\tau}}\right)$ is not exposed to systematic risk and risk of the back-end instrument can be hedged away, a risk-neutral pricing framework is applicable. Or if investors can fully hedge away the risk of $N\left(\overrightarrow{X_{\tau}}\right) V\left(\overrightarrow{X_{\tau}}\right)$, then it is appropriate to use risk-neutral pricing. ${ }^{13}$

It is unlikely that a p-v provision joined with the back-end instrument, $N\left(\overrightarrow{X_{\tau}}\right) V\left(\overrightarrow{X_{\tau}}\right)$, can be perfectly hedged. First, in many cases, there are no instruments or strategies one might use to hedge the relevant state variables, such as accounting performance, market share, or FDA approval. These state variables are imperfectly correlated with stock price and any hope of an approximation with stock-price-based instruments is unlikely to be realized. Indeed, in 2008 , for example, almost $80 \%$ of p-v grants use some measure of accounting performance as a performance metric, either alone or in conjunction with other metrics. Recall the example in Figure 1 of the L3 Communications stock grant based on EPS growth. Second, even if the p-v provision is based solely on stock performance, the ex post payoff function is often nonlinear and complex and the hedging strategy complex and correspondingly expensive to execute in terms of transaction costs. ${ }^{14}$

Accordingly, we construct and implement an approach that uses drift rates predicted from an asset pricing model (APM) and risk-adjusted discounting using that APM. Our approach will be familiar to many, as it is presented in basic form, alongside the risk-neutral approach, in Black and Scholes (1973). When risk-neutral methods are appropriate, both approaches give the same result. Otherwise, our risk-adjusted method accommodates all cases, including those for which risk-neutral

\footnotetext{
${ }^{13}$ This entails jointly drifting the performance metrics $\overrightarrow{X_{t}}$ at the risk-free rate, $r_{f}$, with noise generated according to the drift covariance matrix $\Sigma$, and then discounting values at the end of the performance period back to the grant date using discount rate $\rho=r_{f}$.

${ }^{14}$ Johnson and Tian, (2000) and Kuang and Suijs (2006) provide an analytical solution to a p-v award with a single stock price vesting condition in a risk neutral framework. Bizjak, Kalpathy, and Thompson (2013) and Holden and Kim (2013) provide an analytical solution to p-v awards incorporating some of the features of the ex post payout structure but also in a risk neutral setting.
} 
method is unsuitable. While these calculations are computationally intensive, the risk-adjusted approach is justified on both practical and conceptual grounds. The discount rate is based on exposure of $N\left(\overrightarrow{X_{\tau}}\right) V\left(\overrightarrow{X_{\tau}}\right)$, not just $V\left(\overrightarrow{X_{\tau}}\right)$, to priced risk, at the end of the performance period, per the logic in standard APMs.

Because the applicable discount rate can vary across realizations of the state variables, we write the discount rate as $\rho\left(\overrightarrow{X_{\tau}}\right)$. Ex ante expected value at the grant date is $E\left[N\left(\overrightarrow{X_{\tau}}\right) V\left(\overrightarrow{X_{\tau}}\right) /(1+\right.$ $\left.\left.\rho\left(\overrightarrow{X_{\tau}}\right)\right)^{\tau}\right]$, or in continuous time $E\left[N\left(\overrightarrow{X_{\tau}}\right) V\left(\overrightarrow{X_{\tau}}\right) / e^{\rho\left(\overrightarrow{X_{\tau}}\right) \tau}\right]$, where the expectation is taken across $\overrightarrow{X_{\tau}}$, based on the joint distribution function of $\overrightarrow{r_{X}}, \sim \mathrm{F}(\vec{\mu}, \Sigma)$, initial values $\overrightarrow{X_{0}}$ and estimated parameters $\vec{\mu}, \sum^{15}$

For illustration, consider the simple two-metric case with state variables $\left(A_{t}, P_{t}\right)$ evolving according to $\overrightarrow{r_{X}}, \sim \mathrm{F}(\vec{\mu}, \Sigma)$. Define $\varepsilon_{C D}=(D / C)(\partial C / \partial D)$ as the elasticity of $C$ in $D$, where $C, D=$ $A, R, P, V$, or $N$ and $C \neq D$. Performance metrics are $A$ and $R$ (or $P$ ), $M$ is value of the market portfolio, and $V$ and $N$ are functions given by $V\left(P_{\tau}\right)$ and $N\left(A_{\tau}, R\left(P_{\tau}\right)\right)$. Then the sensitivity of return on the p-v grant to return on the market is

$$
\left[\frac{P_{\tau}}{N\left(A_{\tau}, R\left(P_{\tau}\right)\right) V\left(P_{\tau}\right)}\right]\left[\frac{d\left(N\left(A_{\tau}, R\left(P_{\tau}\right)\right) V\left(P_{\tau}\right)\right)}{d P_{\tau}}\right] \frac{M_{\tau}}{P_{\tau}} \frac{\partial P_{\tau}}{\partial M_{\tau}}
$$

where $M_{\tau}$ is value of the market at time $t=\tau$ and $\left(M_{\tau} / P_{\tau}\right)\left(\partial P_{\tau} / \partial M_{\tau}\right)=\beta_{P M}$, which is the traditional CAPM beta of the firm’s stock return with stock market return.

Turn now to providing an expression for the two bracketed terms of equation (1), which together represent the full elasticity of $N\left(A_{\tau}, R\left(P_{\tau}\right)\right) V\left(P_{\tau}\right)$ in $P_{\tau}$ through all channels. By all channels, we mean directly through $R\left(P_{\tau}\right)$ and also by way of the statistical association, arising from

\footnotetext{
${ }^{15}$ Once the performance period is complete and uncertainty embedded in $N\left(A_{\tau}, P_{\tau}\right)$ is resolved, the grant is worth $N V\left(A_{\tau}, P_{\tau}\right)$ and from that time forward standard risk-neutral valuation methods can be applied.
} 
the economic association between $P_{\tau}$ and the accounting metric, $A_{\tau}$. Time subscripts are suppressed when the meaning is clear and it is convenient. In general, the derivatives are taken at the end of the performance period, $t=\tau$. Differentiating fully, the elasticity of $N\left(A_{\tau}, R\left(P_{\tau}\right)\right) V\left(P_{\tau}\right)$ in $P_{\tau}$ gives

$$
\left[\frac{P}{N V}\right]\left[\frac{d(N V)}{d P}\right]=\left[\frac{P}{N V}\right]\left[N\left(\frac{\partial V}{\partial P}\right)+V\left(\frac{\partial N}{\partial R} \frac{\partial R}{\partial P}+\frac{\partial N}{\partial A} \frac{\partial A}{\partial P}\right)\right]
$$

Rewriting (1), the sensitivity of the return on the p-v grant to return on the market becomes

$$
\left[\frac{P}{N V}\right]\left[\frac{d(N V)}{d P}\right] \frac{M}{P} \frac{\partial P}{\partial M}=\left[\varepsilon_{V P}+\varepsilon_{N R} \varepsilon_{R P}+\varepsilon_{N A} \varepsilon_{A P}\right] \beta_{P M}
$$

Restated, the beta of return on $N\left(A_{\tau}, R\left(P_{\tau}\right)\right) V\left(P_{\tau}\right)$ relative to return on the market is

$$
\beta_{N V, M}=\left[\varepsilon_{V P}+\varepsilon_{N R} \varepsilon_{R P}+\varepsilon_{N A} \varepsilon_{A P}\right] \beta_{P M}
$$

The elasticities $\beta_{P M}$ and $\varepsilon_{A P}=\operatorname{cov}\left(r_{A}, r_{P}\right) / \operatorname{cov}\left(r_{P}, r_{P}\right)$ are measured using historical data on returns on $(A, P)$ and $M$. Using the functional form of the grant schedule, $\varepsilon_{N A}=(A / N)(d N / d A)=$ $(1 / N)\left(d N / d r_{A}\right)$ and $\varepsilon_{N R}=(R / N)(d N / d R)=(1 / N)\left(d N / d r_{R}\right)$. The elasticities in the grant schedule in most cases vary across realizations of $\left(A_{\tau}, P_{\tau}\right) . \varepsilon_{R P}$ is based on the transformation $R\left(P_{\tau}\right)$, with $\varepsilon_{R P}=1$ if $R\left(P_{\tau}\right)=P_{\tau}$. $\varepsilon_{V P}=(P / V)(d V / d P)=d r_{V} / d r_{P}$ can depend on realized $P_{\tau}$. For example, if the back-end security is a simple vested option and adjusted Black-Scholes is appropriate, $\varepsilon_{V P}$ would be based on the derivative of $V\left(A_{\tau}, P_{\tau}\right)=c\left(P_{t}, K, \sigma_{r}, d\left(\mathrm{f}_{t}\right), T-t, r_{f}\right)$ in $P_{\tau}$, a derivative that varies in $P_{\tau}$. On the other hand, $\varepsilon_{V P}=1(0)$ if the back-end instrument is stock (cash) and there are no complications, such as an additional time-vesting restriction. Note that if there is no p-v provision then $\varepsilon_{N R}=\varepsilon_{N A}=0$ and (4) reduces to $\beta_{V N, M}=\varepsilon_{V P} \beta_{P M}$, which is equation (15) in Black and Scholes (1973). 
The form of $\rho\left(\overrightarrow{X_{\tau}}\right)$ (or $\rho\left(A_{\tau}, R\left(P_{\tau}\right)\right)$ ) depends on the asset pricing model. The above calculation of (4), sensitivity of the value of the grant at the end of the performance period to return on the market, is oriented towards a CAPM or CAPM-like market model. ${ }^{16}$ We employ the simple CAPM, $r=r_{f}+\beta_{N V, M}\left[E\left(r_{M}\right)-r_{f}\right]+\tilde{e}$, where $\tilde{e}$ is the error term. Then

$$
\rho\left(A_{\tau}, R\left(P_{\tau}\right)\right)=r_{f}+\beta_{V N, M}\left[E\left(r_{M}\right)-r_{f}\right]=r_{f}+\left[\varepsilon_{V P}+\varepsilon_{N R} \varepsilon_{R P}+\varepsilon_{N A} \varepsilon_{A P}\right] \beta_{P M}\left[E\left(r_{M}\right)-r_{f}\right]
$$

Then, again, ex ante expected value at the grant date is

$$
E\left[N\left(A_{\tau}, R\left(P_{\tau}\right)\right) V\left(P_{\tau}\right) /\left(1+\rho\left(A_{\tau}, R\left(P_{\tau}\right)\right)^{\tau} \mid\left(A_{0}, R\left(P_{0}\right)\right)\right]\right.
$$

To empirically generate the expectation, for each grant schedule in each firm we simulate one million paths in the vector of state variables to the end of the performance period.

\subsection{Estimating the Parameters}

The expectation in (6) requires $\beta_{P M}$, the joint distribution function of $\overrightarrow{r_{X}}, \sim \mathrm{F}(\vec{\mu}, \Sigma)$, initial values $\left(A_{0}, R\left(P_{0}\right)\right)$, estimated parameters $(\vec{\mu}, \Sigma)$, and length of the performance period $\tau$. For any specific vector of state variables $(A, P)$, for the granting firm we estimate the parameters $(\vec{\mu}, \Sigma)$ using five years of quarterly data on $\left(r_{A}, r_{P}\right)$ over $t=-5$ to $t=-1$. We do the same for each other firm in the same two-digit SIC code over the same 20 quarters. ${ }^{17}$ Because the data are noisy and the time series is short (20 quarters), for the granting firm we estimate $(\vec{\mu}, \Sigma)$ as the average across all firms in the same two-digit SIC code. ${ }^{18}$ For the granting firm we estimate $\beta_{P M}=\operatorname{cov}\left(r_{p}, r_{M}\right) / \operatorname{cov}\left(r_{M}, r_{M}\right)$

\footnotetext{
${ }^{16}$ We can extend this approach to the market model, the Fama-French 3-factor model, or the Carhart 4-factor model.

${ }^{17}$ A technical problem arises because earnings drift is not well defined for companies with either zero or negative lagged earnings. If lagged earnings is positive, then we define drift in earnings as change in earnings divided by lagged earnings. If lagged earnings is less than zero then we use the absolute value in the denominator. We do not have this difficulty with sales, which also is frequently used in practice, as it is strictly positive.

${ }^{18}$ We use the industry-level approach for the large-sample analysis in this paper. [Since this study involves large firms, we use the Incentive Lab universe of firms (which encompasses the Execucomp universe) to compute industry averages.]
} 
using three years of weekly data on firm stock return (including dividends) and return on the market.

We use the CRSP value-weighted index as the market index. The risk-free rate is the ten-year Treasury note rate.

\section{Measuring the Incentive Properties of P-V Grants}

\subsection{Marginal and aggregate sensitivity of grant value to stock price}

One conventional way to calculate the pay-performance sensitivity of a stock or option grant (delta) is to calculate the change in value of that grant arising from a $1 \%$ change in stock price. ${ }^{19}$ Likewise, for a p-v grant of stock or options, we perturb initial $P_{0}$ by $1 \%$, simulate ex ante value based on the different initial condition $\left(A_{0},(1.01) P_{0}\right)$, and take the difference between the simulated values based on different initial starting points $\left(\left(A_{0},(1.01) P_{0}\right)\right.$ versus $\left.\left(A_{0}, P_{0}\right)\right)$. This difference indicates the effect on the ex ante expected discounted value of the p-v grant of changing the stock price by $1 \%$. We call this the marginal delta in stock price and denote it as $\delta_{P}$.

We can extend this approach to accounting performance or any other performance metric. As above, we perturb initial $A_{0}$ by $1 \%$, simulate ex ante value based on the different initial condition ((1.01) $\left.A_{0}, P_{0}\right)$ and take the difference between the simulated values based on the different initial starting points. The difference indicates the effect of changing accounting performance (or some other performance metric) by $1 \%$ on the ex ante expected discounted value of the p-v grant. We call this the marginal delta in accounting (or other) performance, denoted as $\delta_{A}$.

\footnotetext{
The benefit of the industry-level approach, absent large differences across companies, is additional precision in the estimates. The cost is that this assumes that all firms in the same industry have the same process generating the state variables. Accordingly, in analyzing awards for individual firms, one can implement an approach that customizes the parameter estimates to better reflect the circumstances of the specific company. Among other things, so as to enhance the precision of the forecast of $(\vec{\mu}, \Sigma)$, the method can use a mix of industry and firm parameters, characteristics of prior grants (including threshold, target, ceiling, and type of metric), and whether the firm achieved critical performance levels specified in prior grants.

${ }^{19}$ For example, see Coles, Daniel, and Naveen (2006) for usage of the semi-elasticity form of pay-performance sensitivity (delta) in the absence of vesting provisions.
} 
Stock performance and other performance metrics, such as accounting performance, often are related. For example, it can be precisely through observable improvements in accounting performance that price discovery in stock markets leads to increased stock price. Empirically, the parameters, estimated using historical data, used to construct $\mathrm{F}(\vec{\mu}, \Sigma)$, represent the relation. For each $1 \%$ change in stock price, on average there will have been some associated change in accounting performance which is the elasticity of $A$ in $P, \varepsilon_{A P}=\operatorname{cov}\left(r_{A}, r_{P}\right) / \operatorname{cov}\left(r_{P}, r_{P}\right)$. Thus, the marginal delta in stock price is an incomplete measure of the sensitivity of the ex ante value of the $\mathrm{p}-\mathrm{v}$ grant to stock price. Accordingly, we perturb initial $P_{0}$ by $1 \%, A_{0}$ by $\varepsilon_{A P} \%$, simulate ex ante value based on the different initial condition $\left(\left(1+0.01 \varepsilon_{A P}\right) A_{0},(1.01) P_{0}\right)$, and take the difference between the simulated values based on the different initial starting points, $\left(\left(1+0.01 \varepsilon_{A P}\right) A_{0},(1.01) P_{0}\right)$ versus $\left(A_{0}, P_{0}\right)$. The difference indicates the effect of changing stock performance by $1 \%$, while also including the associated change in the other performance metric, to measure the full effect of the $1 \%$ change in stock price on the ex ante expected discounted value of the p-v grant. We call this the

aggregate delta in stock performance. $\delta_{A g g}$ to a first order can be approximated by $\delta_{A g g}=$ $\delta_{P}+\varepsilon_{A P} \delta_{A}$, though the expression is approximate because $\delta_{A}$ need not be linear in the size of the perturbation in $A_{0}$. To our knowledge, the marginal delta in accounting (or other) performance and aggregate delta in stock performance are new constructs for measuring incentive alignment.

\subsection{Marginal and aggregate sensitivity of $p$-v grant value to stock return volatility}

The sensitivity of expected value of an award to the volatility of stock performance is seen as a measure of the incentive conveyed by the award to the executive to take risk on behalf of shareholders. One measure of vega is the change in expected value of the award associated with a $1 \%$ proportional change in the annualized standard deviation of stock return (see Anderson and Core, 2013, for example). In the absence of vesting provisions, in general the convexity in payoff 
arising from options is large relative to any convexity arising from shares (Core and Guay, 2002), so historically almost all of vega in an executive's portfolio arose from the accumulation of options net of dispositions. ${ }^{20}$ Below we assess whether p-v provisions are a substitute source of risk-taking incentives when stock grants are displacing options awards.

Recall that $\overrightarrow{r_{X}}=\left(r_{A}, r_{P}\right) \sim \mathrm{F}(\vec{\mu}, \Sigma)$, based on estimated parameters. For a given p-v grant of stock or options, we proportionally increase the square root of the lower right diagonal element of $\Sigma$, $\sqrt{\sigma_{P P}} \equiv \sqrt{\operatorname{cov}\left(r_{P}, r_{P}\right)}$, by $1 \%$ We then simulate ex ante value based on the different initial condition based on (1.01) $\sqrt{\sigma_{P P}}$ and take the difference between the simulated expected values based on different initial starting points $\left((1.01) \sqrt{\sigma_{P P}}\right.$ versus $\sqrt{\sigma_{P P}}$, holding all other parameters constant). This difference indicates the effect of changing the stock return volatility proportionally by $1 \%$ on the ex ante expected discounted value of the p-v grant. We call this the marginal vega in stock price and denote it as $v_{P}$.

Likewise, we calculate the effect of a change in volatility of the accounting (or other) performance metric. We proportionally increase the square root of the upper left diagonal element of $\Sigma$, $\sqrt{\sigma_{A A}} \equiv \sqrt{\operatorname{cov}\left(r_{A}, r_{A}\right)}$, by $1 \%$. We then simulate ex ante value based on the different initial condition based on (1.01) $\sqrt{\sigma_{A A}}$ and take the difference between the simulated expected values based on different initial starting points ((1.01) $\sqrt{\sigma_{A A}}$ versus $\sqrt{\sigma_{A A}}$, holding all other parameters constant). This difference indicates the effect of changing the volatility of drift in the accounting metric proportionally by $1 \%$ on the ex ante expected discounted value of the p-v grant. We call this the marginal vega in the accounting metric and denote it as $v_{A}$.

The marginal vegas ignore the off-diagonal elements of the covariance matrix. To account for the changes in the covariation in performance metrics concurrent with changes in the own

\footnotetext{
${ }^{20}$ See Anderson and Core (2013) for a recent reassessment of this conventional wisdom.
} 
covariances, we apply the analogous procedure to all elements of the covariance matrix. We increase $\sqrt{\sigma_{C D}}$ proportionally by $1 \%$ for each $\mathrm{C}, \mathrm{D}=A, P$. This procedure both acknowledges the covariation of the accounting and stock performance metrics and also maintains the elements in the covariance matrix in the same proportions. ${ }^{21}$ We then simulate ex ante grant value based on the different initial condition using the difference between the simulated expected values based on different initial starting points holding $\vec{\mu}$, constant. We call this aggregate vega and denote it as $v_{\text {Agg. }}$

While $v_{P}$ is well-known, to our knowledge the marginal vega in accounting (or other) metric and aggregate vega are new constructs for measuring the incentives of executives to implement risky firm policy.

\section{Sample Construction}

We obtain from Incentive Lab detailed data from proxy statements (DEF 14A) on the various aspects of all short-term and long-term (vesting term and/or performance period exceeding one year) stock, option, and cash awards to named executive officers (NEOs) over the period 1998-2012. In this paper, we focus on all equity-based awards (stock and options), leaving analysis of cash awards and examination of the choice of term to a later study.

The sample of firms is based on the largest 750 firms, measured by market capitalization, in each of the years 1998-2012. Of course, the set of 750 largest firms changes from year to year. Back- and forward-filling yields 1,833 firms during the period between 1998 and 2012, though data will not be available for some firms in a given year for the usual reasons (e.g., merger, not listed).

\footnotetext{
${ }^{21}$ Another common measure of vega is the change in expected value of the award associated with an absolute 0.01 change in the annualized standard deviation of stock return (see Guay, 1999, and Coles, Daniel, and Naveen, 2006, for example). This approach seems natural when applied to one element of the covariance matrix in isolation of the other elements. Adding 0.01 to multiple elements of the matrix of square roots of the return covariances, however, changes the covariances (and their square roots) relative to one another. Thus, instead we apply proportional changes to measures of covariation.
} 
Of these 1,833 firms, 1,268 (69\%) tie vesting of stock or stock options to stock price, accounting, or other non-financial performance metrics ("performance-based awards") one or more times in the sample period, while almost all firms $(1,793)$ grant t-v stock or options once or more.

The Incentive Lab data contains all the information provided in the proxy statements on the back-end security and on the functional form of the vesting provision. For t-v awards this includes the time horizon of the vesting schedule and whether the shares or options vest uniformly (also known as "ratable") or all at once ("cliff" vesting). For p-v awards the Incentive Lab dataset contains all available information on performance metrics, hurdles, and benchmarks. We obtain stock price and TSR data from CRSP and accounting figures and other information from Compustat. Below we first discuss the characteristics and functioning of the $\mathrm{t}-\mathrm{v}$ and $\mathrm{p}-\mathrm{v}$ awards and then provide information on the characteristics of the firms in our sample and the determinants of usage of $\mathrm{p}-\mathrm{v}$ provisions.

\section{PV Provisions are Displacing Time-Based Vesting Provisions}

Table 1 contains summary statistics on the types of grants these firms make. The frequency counts identify stock versus options and time versus performance vesting. It is apparent that, just as stock awards are displacing option grants, so are p-v awards which are displacing time-vesting awards. Based on pure count, the proportion of firms using p-v awards has more than tripled over the sample period, from $21 \%$ in 1998 to $68 \%$ in 2012 . Based on values reported by the firms themselves in proxy statements, the value of $\mathrm{p}-\mathrm{v}$ grants as a proportion of the value of all equity grants has more than tripled over the same period from $12 \%$ to $41 \% .{ }^{22}$

\footnotetext{
${ }^{22}$ While our focus is on p-v grants, the Incentive Lab dataset also contains information on the types of awards that these grants are coming to displace. Several broad conclusions arise from examination of those data. Among t-v grants, the relative use of cliff vesting versus uniform vesting is declining for both option and stock awards. Ratable option and stock awards predominantly vest uniformly over either four, three, or five year periods, in declining order of frequency.
} 
Table 2 provides detailed evidence on the usage and characteristics of $\mathrm{p}-\mathrm{v}$ grants through time. As Panel A indicates, the yearly number of firms with $\mathrm{p}-\mathrm{v}$ grants has more than doubled over the period 1998 to 2012. Like t-v grants, for p-v grants stock is displacing options as the back-end security.

\section{The Evolution of PV Characteristics (Contractual Terms) Pre- and Post-FAS 123R}

The largest number in Panel A of Table 3 is 739, which is the number of firms that grant restricted stock with a conditional vesting provision in 2012. Relative to accelerated p-v provisions, usage of contingent p-v provisions has increased from $72.8 \%$ to $98.8 \%$. Our analysis focuses on the bulk of the data, specifically conditional rather than accelerated p-v awards. Thus, Panels B - E are based on the subset of conditional $\mathrm{p}-\mathrm{v}$ grants. Panel $\mathrm{B}$ indicates that the usage of $\mathrm{p}-\mathrm{v}$ accounting hurdles has displaced to some extent stock price hurdles. Among p-v grants, more than three in four use an accounting hurdle alone or in conjunction with one or more other performance measure(s). Note that the figures in Panel B add up to more than $100 \%$ because some awards use multiple performance criteria. Panel C shows the wide spectrum of accounting metrics employed. Some measure of earnings is used in about two-thirds of instances in which an accounting-based p-v provision is employed, while some accounting rate of return is used in about one-quarter of cases. A cash-flow metric appears $13.1 \%$ of the time in the sample period. Panel D suggests that companies employ a significant portion of the wide range of design possibilities presented by p-v provisions. Though we do not assess the question here, performance metrics, including stock price and accounting measures, likely reflect a range of operational and strategic objectives.

For cliff vesting grants of stock or options, companies have moved away from immediate vesting to a longer horizon, most frequently cliff vesting at three years from the grant date. Information on t-v grants is available from the authors. 
Panel E indicates that absolute awards continue to outnumber relative awards by almost two to one. Thus, we concentrate in what follows on absolute awards. Nonetheless, Panel E shows that explicit relative performance evaluation has been a nontrivial and persistent aspect of executive compensation. Bettis, Bizjak, Coles, and Young (2013) treat relative awards in detail.

There is a significant regulatory component in these trends. ASC 718, which took full effect in 2005 as FAS123R, removed the preferential treatment in reporting and expensing given to options over restricted stock. In addition, ASC 718 allows additional flexibility in reporting and expensing for p-v grants that use any hurdle not based on stock price. For equity awards with stock price vesting conditions, firms must produce a valuation that incorporates all characteristics of both the back-end instrument and the grant schedule. For example, the value of a restricted stock award that fully vests contingent only on achieving a certain level of stock price performance would need to be valued incorporating the barrier condition on vesting. This value would be reported as the Grant Date Fair Value (GDFV) in the proxy statement. ${ }^{23}$ In contrast, no formal valuation need be conducted if the vesting condition is based on at least one metric other than stock price. For these types of awards, the firm typically reports a value for the award that appears not to incorporate the specific features of the vesting provision. For example, for a restricted stock (option) award with an accounting vesting condition, the most common valuation reported would be the stock price (Black Scholes value) on the grant date times a target number of the back-end units. ${ }^{24}$ Per Table 2, the data on both t-v and p-v grants are consistent with the notion that ASC 718 is in part responsible for a

\footnotetext{
${ }^{23}$ Firms can use different methodologies as long as they are based on sound economic theory and practice. In the case of a restricted stock award with a stock price vesting condition, one allowed approach is Monte Carlo simulation incorporating the first and second moments of the stock price path along with the vesting hurdle condition. A firm also can use a closed form solution if one is available.

${ }^{24}$ The reason behind the discrepancy in reporting based on the vesting characteristic appears to be due to the fact that there are acceptable and "well-established" valuation techniques for valuing equity awards with stock price vesting conditions (e.g., a barrier option), but that the analogous techniques for equity awards with other types of performance metrics (e.g., sales growth) are undeveloped or nonexistent.
} 
move away from options to stock and, for $\mathrm{p}-\mathrm{v}$ grants, a move towards accounting performance metrics. $^{25,26}$

\section{The Implications of PV Provisions for the Value of Executive Compensation}

One possibility is that $\mathrm{p}-\mathrm{v}$ provisions are inconsequential and instead are just windowdressing to appease critics who assert time-vesting is simply pay-for-pulse. If so, then the implications of $\mathrm{p}-\mathrm{v}$ provisions for grant value, alignment of executive incentives with shareholder interests (delta), and incentives for executives to select and implement risky financial and investment policy (vega) of the award are likely to be negligible. We now apply the methods developed in Sections 3 and 4 to obtain hurdle hit rates, value, and marginal and aggregate delta and vega for $\mathrm{p}-\mathrm{v}$ awards. Again, we restrict our analysis to awards of stock and options with absolute, conditional vesting provisions. While our approach is applicable to more complex awards, for simplicity we narrow our attention to $\mathrm{p}-\mathrm{v}$ grants contingent on one or two performance metrics for which we have full information on grant schedule. Recall that, per Table 2, many p-v grants are contingent on a single accounting performance metric.

In simulating paths of the state variable(s) to generate estimates of the probability of achieving important performance benchmarks, such as a threshold or ceiling, we use actual drift rates of the stock and accounting performance metrics. Moreover, because a risk-free hedge is likely to be expensive or impossible to construct, we use a risk-adjusted approach to simulate ex ante grant value, delta, and vega. We simulate stock prices and accounting measures (namely, earnings or sales) based on a univariate (one measure and set of hurdles) or bivariate distribution (two

\footnotetext{
${ }^{25}$ See Hayes, Lemmon, and Qiu (2012) and BBCK (2010) for discussion of FAS 123R.

${ }^{26}$ That p-v grants are displacing t-v grants also suggests that an examination of one type of award in isolation of the other can suffer from selection bias. For example, does the displacement of $\mathrm{t}-\mathrm{v}$ with $\mathrm{p}-\mathrm{v}$ provisions alter the conclusions in Cadman, Rusticus, and Sunder (2013) on whether stock-option expense recognition influences the choice of the form of time-vesting?
} 
performance measures and associated hurdles). We assume drift in any accounting metric (except for sales) is normally distributed while stock return and drift in sales are log-normally distributed. We simulate one million state variable paths over the performance period. The parameters required for simulation are the annual drift rates of the stock and accounting metrics, the annual volatility of performance metric drift, and, when the grant schedule depends on the accounting metric, the correlation of the drifts. Because we follow accounting and stock metrics over the performance period following the award date, for value, delta, and vega calculations we analyze awards with grant dates up through 2008.

Table 3 facilitates an initial assessment of whether p-v provisions are consequential. Recall the example of the 2008 Amgen award, which specifies performance and number of shares granted at a threshold, target and ceiling (maximum). Not all p-v grants contain all three hurdles, but all grants specify at least one of the three. For our sample of 4,225 conditional p-v awards based on one or the other of an accounting or stock price performance metric, Table 3 reports results on simulated and actual p-v hit rates for these hurdles. The mean annualized threshold, target, and ceiling hurdles require that performance improve by $12.4 \%, 15.5 \%$, and $19.1 \%$ per year, respectively, over an average performance horizon of 2.36 years (these include all the different performance metrics). The annual hurdle rates tend to be lower but cover a longer performance period for stock price metrics versus accounting metrics and for options relative to stock as the back-end instrument.

Simulated and ex post probabilities of making the threshold, target, and ceiling standards over the performance period indicate that the hurdles are nontrivial. Per Table 3, the mean simulated probabilities of vesting at threshold, target, and ceiling are $0.44,0.40$, and 0.36 , respectively. The simulated values are very similar to the $0.46,0.41$, and 0.39 average actual hit rates. The simulated hurdle hit rates also are very close for the subclasses of grants reported in Table 3. 
One simple approach to valuing the stock or option grant would be to apply a "haircut," based on the likelihood of meeting target performance, to the value of the stock or options at target (target number of units times value per unit at target performance). Doing so with the simulated (actual) average would imply an average reduction in value of the p-v award of 59.9\% (58.9\%) versus target. Of course, this calculation is misleading insofar as the performance measures on which the p-v provision is based can be the same as, or be correlated with, the determinants of value of the stock or options, specifically stock price. Moreover, for a convex grant schedule, the upside between target and ceiling can be significantly different from the downside between threshold and target. For the 2008 Amgen p-v stock grant, for example, moving from threshold to target performance earns an additional 36,500 shares for an increase in annualized TSR of 8.0\% per year, while moving from target to ceiling performance yields an additional 73,000 shares for a further increase in annual TSR of $10 \%$.

Table 4 provides estimates of ex ante award value for the subset of single-metric p-v grants. The calculations account for correlation between the number of units granted and value of the backend instrument, functional form, including asymmetries and nonlinearities of the p-v grant schedule, and exposure of $N\left(P_{\tau}\right) V\left(P_{\tau}\right)$ or $N\left(A_{\tau}\right) V\left(P_{\tau}\right)$ to systematic risk. Including characteristics of the p-v grant schedule and using risk-adjusted simulation methods and discounting makes a large difference. For comparability across the 4,225 single-metric grants, we normalize the back-end instrument and p-v grant schedule by assuming a grant date stock price of $\$ 1$, an option exercise price of $\$ 1$, and a benchmark of 1.0 units (stock or options) granted at target. Thus, the benchmark value of a stock grant absent the $\mathrm{p}-\mathrm{v}$ provision is $\$ 1$, while the value of the benchmark at-the money option, given by the Black-Scholes formula, is $\$ 0.55$. In comparison, the average p-v stock (option) award is worth $\$ 0.61$ (\$0.39). Aggregating the awards, the average value without the $\mathrm{p}-\mathrm{v}$ provision is $\$ 0.95$ versus 
$\$ 0.59$ when the p-v provision is included. The haircut on average should be about $41 \%$, as compared to the naïve haircut of nearly $60 \%$ of target suggested by Table 3 .

Table 5 compares the value disclosed by firms with our estimates of value (not normalized) with and without the single-metric p-v provision, aggregated and in subsamples depending on the type of performance metric (accounting or stock) and by the back-end security (stock or option). Following the change in the reporting requirements adopted by the SEC in 2006, companies are now required to disclose the grant date fair value (GDFV) for all awards. Thus, for 2,835 of the 4,225 single-metric conditional awards represented in our sample, firms disclose a GDFV. Table 5 indicates that correlation of the value of the back-end instrument and grant schedule, asymmetry of the grant schedule, and exposure of ex post value to market risk, diminish the accuracy of reporting by firms of the value of $\mathrm{p}-\mathrm{v}$ grants.

For equity-based (stock or options) awards with stock price conditions, companies are required to provide a valuation that explicitly incorporates the characteristics of the back end instrument and the vesting condition. For the $484 \mathrm{p}-\mathrm{v}$ grants of restricted stock and stock options based on a single performance metric contingent on stock price, the company on average reports $\$ 1,584,074$, which is significantly less than the average simulated estimate without the p-v provisions of $\$ 2,768,983$. Based on these averages, companies report a significant haircut for the p$\mathrm{v}$ provision of $42.8 \%$. In contrast, our average estimate of value when including the effects of the p$\mathrm{v}$ provision is $\$ 1,980,617$, which is $71.5 \%$ (or a $28.5 \%$ haircut) of the value without the performance condition(s) in place. On average, companies apply a somewhat larger haircut to p-v grants based only on stock price than is appropriate. ${ }^{27}$

\footnotetext{
${ }^{27}$ For these awards, one potential reason that our valuations are higher compared to what the firm provides in the proxy is that firms have discretion over the value of the inputs that go into the valuation model (e.g., volatility). For both expensing and reporting purposes there is incentive for the firm to select model inputs that lower the value of an award. See Bettis, Bizjak, Coles and Young (2012) for analysis of whether firms behave opportunistically when expensing
} 
For 2,351 p-v grants based on a single measure of accounting performance, the average disclosed value, simulated value without the performance condition(s), and simulated value based on the performance condition(s) are, respectively, $\$ 1,112,330, \$ 1,642,947$, and $\$ 934,703$. The difference between disclosed value and value excluding the performance condition(s) is a haircut of $32.3 \%$, whereas our calculation of the average appropriate discount is $43.1 \%$ ( $\$ 934,703$ versus $\$ 1,642,947)$. It appears that, for whatever reason, companies report a higher value for compensation expense for $\mathrm{p}-\mathrm{v}$ awards based on accounting performance than they might otherwise. Currently there are no well-accepted techniques to value awards with accounting based metrics or other types of non-market based vesting conditions. This is one of the reasons why FASB does not require these awards to be valued incorporating the specific vesting conditions. Moreover, to our knowledge there has been no guidance by FASB as to what type of haircut, if any, can be applied to these types of awards. Since a reported grant date fair value is required and the approach presented herein is somewhat complex, firms may be left with little alternative but to give less than full consideration to the effect of vesting conditions and, instead, report something larger.

In summary, our calculations indicate that $\mathrm{p}-\mathrm{v}$ provisions have a significant effect on the value of a stock or option grants to an NEO. The appropriate discount on average can be as large as 46.2\% for some classes of awards ( $\mathrm{p}-\mathrm{v}$ option awards, per Table 5). Moreover, company disclosed values have imperfect connection to estimates that explicitly include the performance condition(s), especially for p-v awards tied to accounting conditions. The results for both accounting and stock performance metrics highlight the need for a framework that can provide an accurate economic value of p-v instruments.

equity awards. Another explanation for the difference in values is that firms typically use a risk neutral valuation framework. 
Our findings are relevant for investors and regulators who are interested in understanding the value of executive pay. As we emphasize, valuation reported in the proxy statement does not necessarily reflect the value of these awards. The above findings also are important to academic research. In particular, studies that use the reported GDFV in proxies are likely to suffer from measurement error that potentially contaminates inference. Moreover, the measurement error could be related in the cross section to firm characteristics so that empirical models are misspecified.

\section{The Implications of P-V Provisions for Executive Incentives}

\subsection{The effect of single-metric p-v provisions on the incentive properties of equity-based awards to executives}

Tables 6 and 7 report our calculations of the effect on incentives of p-v conditions. Our approach herein is to measure the implications for executive delta and vega from each individual p-v grant. $^{28}$ For simplicity, for now we restrict our analysis to contingent $\mathrm{p}-\mathrm{v}$ grants based on one performance metric. Table 6 reports marginal stock price and accounting deltas, $\delta_{P}$ and $\delta_{A}$, and aggregate delta, $\delta_{A g g}$, as defined in Section 4.1. Table 7 provides marginal stock and accounting vegas, $v_{P}$ and $v_{A}$, and aggregate vega, $v_{A g g}$, all as set forth in Section 4.2.

One benchmark grant for assessing the values of delta and vega is the target grant without the p-v contingency. In addition, in some calculations of p-v marginal and aggregate delta and vega we remove the effect of the p-v value haircut on the incentive property calculations by multiplying the delta or vega of the p-v grant times the ratio of the simulated value of the grant in the absence of the

\footnotetext{
${ }^{28}$ To measure the overall incentives of the executive to provide managerial input and take risk, meaning accumulated delta and vega, one would apply our approach to the accumulated portfolio of all $\mathrm{p}-\mathrm{v}$ and $\mathrm{t}-\mathrm{v}$ grants net of dispositions. For calculation of the sensitivity of the executive's portfolio of accumulated non-p-v stock and options net of dispositions to stock price, see Guay (1999), Core and Guay (2002), and Coles, Daniel, and Naveen (2006), for example. For non-p-v vega, illustrative studies include Core and Guay (2002), Coles, Daniel, and Naveen (2006), and Anderson and Core (2013).
} 
provision divided by the simulated value with the $\mathrm{p}-\mathrm{v}$ provision (see Table 4 ). In other words, to isolate the effects of the $\mathrm{p}-\mathrm{v}$ provision, we compare grants with equal value.

Consider first the $783 \mathrm{p}-\mathrm{v}$ grants of stock with a grant schedule contingent on stock performance. Column 5 of Panel A of Table 6 indicates that the effect on marginal stock delta of the average stock performance $\mathrm{p}-\mathrm{v}$ provision is statistically large. The marginal delta of a value-neutral stock-performance-based p-v stock grant is about $103 \%$ larger with ( $\left.\delta_{S}=\$ 65,354\right)$ versus without $\left(\delta_{S}=\$ 25,300\right)$ the $\mathrm{p}-\mathrm{v}$ provisions. Without adjusting for the haircut, on average p-v stock price delta would be about $1.50(\$ 37,919 / \$ 25,300)$ times the delta of the award absent the performance conditions. Likewise, though the difference is not as large, p-v option grants based on stock price, holding value constant, convey significant marginal stock price delta.

For a p-v award based on accounting performance, marginal stock delta arises only through the sensitivity of the value of the back-end instrument to stock price, with a scaling factor based on a certain accounting performance flowing through the grant schedule. For a p-v stock grant based on an accounting metric, marginal stock price delta for the value-neutral grant and the grant unencumbered by $\mathrm{p}-\mathrm{v}$ provision are the same (column 4). Unadjusted for value, the $\mathrm{p}-\mathrm{v}$ grant conveys less marginal stock price delta than the same grant unencumbered. Similar results arise when comparing p-v option grants based on accounting metrics.

Panel B reports results for our new measure of the sensitivity of the value of an award to accounting performance. Stock and option grants with no p-v provision have no direct exposure to accounting performance. In contrast, as rows 1 and 3 indicate, a p-v grant schedule explicitly dependent on accounting performance exposes the value of the grant to the accounting metric. With no basis for comparison available in prior literature, it is difficult to assess the economic significance of marginal accounting delta. 
The calculation of aggregate delta, however, does place accounting delta next to stock price delta. Panel C reports aggregate delta for $\mathrm{p}-\mathrm{v}$ grants based solely on an accounting performance metric. For such grants, stock performance directly affects the value of the stock or options awarded, measured by $\delta_{S}$, and accounting performance has a direct affect through the grant schedule, per $\delta_{A}$. For a given change in stock price, there is an associated probabilistically "normal" change in accounting performance, given by $\varepsilon_{A P}$. Aggregate delta captures the sensitivity of the value of a grant to stock performance through both channels, which is approximately $\delta_{A g g} \cong \delta_{P}+\varepsilon_{A P} \delta_{A}$. By way of illustration consider the 2,827 p-v awards of restricted stock based on an accounting metric. Comparing value-neutral grants across Panels $\mathrm{C}$ and $\mathrm{A}, \delta_{A g g}=\$ 39,850$ versus $\delta_{P}=\$ 23,146$. For stock as the back-end instrument, the accounting metric p-v provision conveys an additional $72 \%$ sensitivity to stock price through the indirect accounting channel. The increase in delta for $\mathrm{p}-\mathrm{v}$ option grants from the accounting channel is even larger (97\%), with $\delta_{A g g}=\$ 115,981$ versus $\delta_{P}=$ $\$ 58,756$.

Given that the accounting channel contributes significant exposure to shareholder wealth, note that a value-neutral comparison of aggregate delta indicates accounting p-v grants of stock and options convey significantly higher incentive alignment to executives than non-p-v grants. On average, for accounting p-v grants of stock (options) $\delta_{A g g}=\$ 39,850$ (\$115,981), as compared to $\delta_{A g g}=\$ 23,146(\$ 58,756)$ for the value-equivalent non-p-v awards. Overall, the above comparisons indicate that the accounting channel is an important source of alignment of managerial incentives with shareholder interests and including that channel has a significant effect on measured NEO incentive alignment.

Table 7 reports the marginal and aggregate vegas for the p-v awards and the value-adjusted $\mathrm{p}-\mathrm{v}$ awards compared to the awards absent the $\mathrm{p}-\mathrm{v}$ provision. For some types of grants, $\mathrm{p}-\mathrm{v}$ awards 
convey significantly more marginal stock return vega than the corresponding non-p-v award. For example, ignoring the very small vega arising from levered equity (per Core and Guay, 2002), all of any vega from a stock grant with a performance condition based on a stock price metric arises from the p-v provision (Panel A, column 5). Likewise, per Panel A (column 3), a value neutral p-v option grant on average has $59 \%$ more vega than the corresponding non-p-v grant $\left(v_{P}=\$ 16,995\right.$ versus \$11,957).

Of course, performance conditions based on an accounting metric convey no marginal vega in volatility of stock return (Panel A, column 4). In contrast, as Panel B indicates, accounting-based p-v grants, regardless of the back-end instrument, convey the incentive to increase accounting return volatility.

Recollect that aggregate vega scales up the elements of the covariance matrix in equal proportions. For p-v awards based on a single accounting metric, Panel C communicates both the relevance of $\mathrm{p}-\mathrm{v}$ provisions in providing overall risk-taking incentives and also the role of accounting p-v provisions as they add such incentives over and above those that arise directly from convexity of the award pay-off in stock performance. For the latter, for example, comparing Panels A and C for option grants based on accounting performance, $v_{\text {Agg }}=\$ 52,086$ while $v_{P}=\$ 12,568$. So, on average, for this class of $\mathrm{p}-\mathrm{v}$ grants, aggregate vega is 314\% larger than traditionally defined marginal stock return vega. Per column 1 of Panel C, average aggregate vega is $474 \%$ larger than it would be, holding grant value constant, if measured without regard for the p-v provision, while aggregate vega of a value-neutral $\mathrm{p}-\mathrm{v}$ grant is nearly 22 times that of the comparable grant non-p-v grant.

\subsection{The effect of double-metric p-v provisions on the incentive properties of equity-based awards to executives}


P-v provisions often are contingent on more than one performance metric. As described in Section 3.1, we find several variants of multi-metric grant schedules in the data. In Table 8 we examine simple representative two-metric grants based on one accounting metric and one stock price metric. Panel A reports mean numbers for three representative "min" cases involving an "AND" condition (see Section 3.1). The level set of the grant schedule in the two performance metrics for these grants is a right-angle. Panel B reports mean numbers for three representative "max" cases involving an "OR" condition. The grant schedule level set in the two metrics is a right-angle inverted in relation to the metric axes. Both panels contain in column $1 \mathrm{a}$ benchmark grant absent the p-v provision valued at the target number of units. Column 3 in Panel A contains an additional hypothetical comparison grant made up of two side-by-side grants, each based on the analogous single-metric grant schedule, for each of the stock and accounting metrics, that would be obtained in the absence of the other performance metric. The assumed allocation of this more flexible grant is $50 \%$ of target units to each side-by-side grant schedule.

As Panel A indicates, the average "Min" p-v grant is worth only about one quarter of the value of the grant unencumbered by the p-v provision. Even so, the "Min" p-v grant delivers about the same marginal delta and double the marginal vega. Such double-metric grants appear to be a relatively inexpensive way to convey to executives the incentives to increase value and take risk. Note that the accounting channel adds only modest increases in these incentives. The average hypothetical analogous side-by-side grant is worth about twice as much as the "Min" p-v grant, the reason being that the hypothetical grant allows a more flexible tradeoff across the performance metrics (versus the right-angled level set) in terms of earning a larger number of units of stock or options. 
Panel B shows some results for double-metric grants for which the number of units granted is based on obtaining one or the other (or both) of the performance goals associated with the two metrics. Such grants allow extreme flexibility in trading of units earned from the two metrics. Accordingly, on average the value of the award is very similar with versus without the p-v provision. In contrast, the "Max" p-v provision significantly increases both delta and vega.

Other awards are significantly more complex than these "simple" multi-metric examples. While we do not report the results in this paper, in general, as in Table 8 for simple representative two-metric p-v provisions, we find that complex p-v provisions reduce the value of the grant and imply large departures in value from what is reported in financial statements. Moreover, similar to

the results in Table 8, complex p-v provisions have significant effects on the incentive properties of awards of stock and options to executives.

\subsection{Grant vega and risk-taking incentives through time}

Hayes, Lemmon, and Qiu (2012) examine compensation convexity and firm risk around the implementation of FAS 123R in 2005. FAS 123R (now ASC 718) represents an exogenous change in the "accounting benefits" of stock options that should have had no effect on the economic costs and benefits of using options to provide executives with the incentive to take risk. Hayes, Lemmon, and Qiu (2012) find that all firms dramatically reduce their usage of stock options after the adoption of FAS 123R but find little evidence that the decline in option usage following the accounting change results in less risky investment and financial policies. Under the assumption that risk-taking incentives come primarily from options, Hayes, Lemmon, and Qiu (2012) interpret their results as offering little support for the view that the convexity in option-based compensation implements risktaking by executives on behalf of shareholders. 
Tables 7 and 8 indicate that p-v provisions significantly amplify standard and new measures of the incentive of executives to take risk. That is, p-v provisions significantly affect the convexity of executive payoff in firm performance. Moreover, while Table 1 and Frydman and Jenter (2010) indicate that firms issue fewer option grants through time, it also indicates that $\mathrm{p}-\mathrm{v}$ usage has increased substantially. Hayes, Lemmon, and Qiu (2012) also touch on p-v provisions, though their analysis does not measure the contribution to compensation convexity of p-v provisions.

Thus, we track through time around ASC 718 (FAS 123R, 2005) the convexity (vega) in yearly pay conveyed to executives by grants of stock and options with and without p-v provisions and aggregated. We report: aggregate vega provided by all option grants with no adjustment for the structure of any p-v provisions; aggregate vega provided by all stock and option grants, including adjustment for vega arising from p-v grants with a single accounting or stock performance metric; and aggregate vega provided by all stock and option grants, including adjustment for vega arising from value-neutral p-v grants with a single accounting or stock performance metric. See Figure 5. The figure indicates average grant vega, even without including the effects of conditional p-v provisions, does not decline much around 2005. More importantly, when including the effects of p-v provisions the decline in average award vega in 2005 is smaller and vega rebounds quickly thereafter. Vega arising from p-v provisions is nontrivial and excluding that source of vega will cause measured vega to underestimate the incentive of executives to take risk. Value-adjusted vega actually increases around 2005.

While this is suggestive, this coarse examination of the time series does not indicate whether cross-sectional variation in vega, correctly measured through inclusion of vega from p-v provisions, explains cross-sectional variation in firm risk and policy. This sort of analysis, per Coles, Daniel, and Naveen (2006), would be required to further illuminate the connection between vega and risk- 
taking. In the meantime, while option usage has declined since 2006, our analysis indicates that compensation convexity has not fallen as much as previously thought, which potentially explains the lack of decline in firm risk-taking after 2006 that is purported by Hayes, Lemmon, and Qiu (2012) to be a puzzle.

\section{The Determinants of Usage and Contract Design}

In this section we characterize and explain cross-sectional and time-series usage patterns of $\mathrm{p}-\mathrm{v}$ provisions and $\mathrm{p}-\mathrm{v}$ contract design. It is precisely pressures from regulators and investors, along with innovation in contracting, which underlies our identification strategy for our analysis of $\mathrm{p}-\mathrm{v}$ adoption in this section and of firm performance as a function of usage in Section 11. First, we develop new hypotheses and identify testable hypotheses from prior contributions to the literature. Second, we report the results of our empirical tests. Herein we use data from all years, 1998 - 2012.

\subsection{The propensity to use performance-vesting provisions}

Conditional absolute p-v provisions, per Tables 7 and 8, convey substantial vega. Thus, such p-v provisions are more likely to be employed when it is optimal to induce risky investment or financial policy. Based on these arguments, Coles, Daniel, and Naveen (2006) find an association between firm risk and R\&D-intensity, on the one hand, and the vega of the executives' portfolios of accumulated stock and options. The notion of conveying vega to NEOs has particular force in the context of recent accounting changes. Prior to the adoption of ASC 718 (FAS 123R), fixed option awards, with a fixed number of options and exercise price both known at the grant date, were to be expensed using the intrinsic value method, where intrinsic value is the difference between stock

price and option exercise price. Because almost all options were issued at the money, firms recorded 
no compensation expense under this method when issuing at the money options. Under ASC 718, the compensation cost of all employee stock options is measured using fair value, so fixed options now imply a compensation expense on the income statement. ${ }^{29}$ As FAS $123 \mathrm{R}$ eliminated the favorable accounting treatment previously accorded option grants, stock grants have displaced option grants. To the extent, however, that companies still find it desirable to manage the incentives of executives to take risks, then conveying vega in some way other than by using options is required. Moreover, leveling the playing field likely provided companies with the opportunity to experiment with vesting metrics in order to improve contract design. Our hypothesis is that $\mathrm{p}-\mathrm{v}$ provisions are used more frequently after 2005, particularly in conjunction with awards to executives of stock. This accounting change should be considered exogenous in the context of our empirical design.

We find in the data that performance-vesting provisions can be complex. Such complexity can be costly to engineer and understand. Larger firms have the scale to amortize the costs of contract design and are more likely to have a need for more complex contract design. Holding firm size constant, compensation consultants have the expertise to deliver complex contracts. More complexity in the contract is likely to be associated with higher fees, so compensation consultants will be disposed to vend complex contract designs. Thus, we hypothesize that larger firms, firms that use a compensation consultant, and firms that use one of the larger, perhaps more sophisticated compensation consultants, are more likely to make p-v awards rather than traditional t-v awards.

BBCK (2010) offer and test several other hypotheses in their earlier dataset of step-function p-v grants. We follow them in testing whether performance-vesting provisions are more likely when

\footnotetext{
${ }^{29}$ In contrast, the accounting for other forms of equity-based awards, including both fixed awards of stock and p-v awards of stock and options, was affected less by ASC 718 (FAS 123R), so the prior advantage to using options relative to other awards has been diminished as of 2005. Indeed, if FAS 123R affected p-v awards at all the effect is favorable, insofar as it allows more discretion to the firm in reporting than prior. These factors combine to imply that a p-V provision attached to an equity-based award is likely to be the best means to impose convexity in compensation on executives. See Hayes, Lemmon, and Qiu (2012) and the appendix in BBCK (2010) for a more complete discussion of the accounting treatment of equity awards prior to FAS 123R.
} 
a CEO is new or recently hired. Their idea is that, while a new CEO will have been carefully scrutinized, it still is likely that the board and shareholders know relatively little about whether the capabilities of a new CEO truly are a good match for the firm. If the CEO is a good fit and the company is successful, the vesting hurdle will be surmounted, the stock or options vest and are more valuable anyway, so the CEO is rewarded. On the other hand, if the firm and CEO are unsuccessful in creating value and the posterior perception of CEO fit is unfavorable, the options and stock with p-v provisions are less likely to have vested early or at all. In this case, the CEO can depart, voluntarily or otherwise, without carrying away large value in the form of vested stock or options. Though our intuition is that this hypothesis applies with more force to the all-or-none grant structure that dominates the BBCK (2010) data, nonetheless we test the hypothesis in our more recent data containing more "continuous" p-v provisions. BBCK (2010) also pose and test the hypothesis that poor prior performance is associated with subsequent usage of $\mathrm{p}-\mathrm{v}$ awards. The idea is that poor performance possibly was a result of poorly structured contracts and that the subsequent usage of p-v grants is one element of actions taken by the firm to improve contract design. The results in BBCK (2010) support the New-CEO, firm complexity, and poor-prior-performance hypotheses. Some of our specifications also control for board size, board independence, CEO duality, institutional ownership, and other governance characteristics. We also control for whether other firms in the industry and interlocking relationships among boards members across firms make p-v awards more likely so as to capture any learning or contagion effect.

Table 9 provides summary statistics on the explanatory variables for $\mathrm{p}-\mathrm{v}$ users versus $\mathrm{t}-\mathrm{v}$ users. Table 10 reports the results for our logit specifications, with the model predicting whether the award to the executive uses performance vesting as opposed to time vesting. We include industry and year fixed effects and correct the standard errors for clustering at the firm level. 
Based on the full sample, the parameter estimates on the indicator for post-2005 are always positive and significant. This provides strong support for our hypothesis on recent accounting changes and the desire to grant fewer options but still convey vega to executives as combining to increase p-v provision usage.

To examine this more directly, we regress the change in proportion of value of executive pay arising from p-v stock grants on the change in proportion of pay arising from t-v options, the same change in proportion interacted with an indicator for post 2005, with controls, to obtain the following.

$$
\begin{aligned}
\Delta\left[\frac{P-V \text { Stock Pay }}{\text { Total Pay }}\right]= & 0.051+0.026 \times \text { Post } 2005-0.103 \Delta\left[\frac{T-V \text { Option Pay }}{\text { Total Pay }}\right] \\
& -0.141 \text { Post } 2005 \times \Delta\left[\frac{T-V \text { Option Pay }}{\text { Total Pay }}\right]+\text { Controls }
\end{aligned}
$$

The estimated coefficients are negative and highly significant for both the linear term $(t=-9.61)$ and interaction term $(\mathrm{t}=-6.94)$. The estimates indicate substitution out of $\mathrm{t}-\mathrm{v}$ options into $\mathrm{p}-\mathrm{v}$ stock, especially after 2005. Overall, these results clarify the puzzle set forth in Hayes, Lemmon, and Qiu (2012). Our explanation (for not finding a connection between option grants and risk-taking) is that vega is provided after 2005 mainly by p-v awards of stock, which are not included in their data, rather than by $\mathrm{t}-\mathrm{v}$ option grants.

Table 10 also reports results when the specifications include indicator variables for whether the firm uses a compensation consultant and for whether the compensation consultant is among the top seven consultants based on market share. Keep in mind that we have data on compensation consultants only for 2006 - 2012. In all three empirical models in Table 10, the coefficient on the large compensation consultant indicator is positive and highly significant, and the coefficient on the 
indicator for using a compensation consultant at all is positive in all three cases and statistically significant at the one percent level in two models.

Firm size, as measured by the logarithm of market capitalization of equity, is positive and significant at one percent in four of six specifications in Table 10. We conjecture that the additional controls used in models 3 and 6 are correlated with firm size (and use of a compensation consultant), so that multicollinearity reduces the significance of the coefficient on firm size and the compensation consultant dummy. Nonetheless, overall, the results provide support for our hypotheses that p-v usage is positively related to firm size, the use of a compensation consultant, and the presence of a compensation consultant with high market share.

In addition to the new hypotheses developed herein, the results in Table 10 are roughly consistent with the findings in BBCK (2010). In particular, the coefficient estimates indicate p-v usage is positively related to CEO newness and some measures of complexity (specifically number of business segments $(+)$ ), and prior poor performance, though several of these results fail to hold once the specifications also include compensation consultant variables. The largest surprise in our results compared to those in BBCK (2010) is that they find a positive and significant coefficient on stock return volatility, while in most specifications we find a negative coefficient that is significant at the one percent level. We do not have an explanation for the difference. Potential reasons include a larger data set, $\mathrm{p}-\mathrm{v}$ provisions that differ significantly in the form of grant schedule from those in BBCK (2010), and a political environment that treats corporate and executive risk-taking differently than during the internet bubble. BBCK (2010) find no relation between p-v usage and investment to assets, while we tend to find a negative relation.

Governance variables that appear always or in some cases to be associated with the propensity to use performance conditions include board independence $(+)$, board size $(+), 5 \%$ - 
holdings by institutions (+), and CEO ownership (-). External factors include whether there is a director interlock with a firm that uses p-v provisions $(+)$ and industry usage $(+) .{ }^{30}$

\subsection{The propensity to use accounting metrics versus stock price metrics}

Table 11 reports results consistent with our hypothesis that accounting metrics displace stock price metrics and hurdles after 2005. For the sample restricted to p-v provisions with one accounting or one stock price hurdle, the sign on the Post-2005 indicator is positive and highly significant. Around FAS 123R, as stock displaced options and p-v awards displaced traditional t-v awards, so did p-v accounting hurdles displace p-v stock price hurdles. See Bennett, Bettis, Gopalan, and Milbourn (2013) for a more comprehensive analysis of the important questions of selection of performance metric and implications of that choice.

\subsection{The propensity to disclose}

Some firms provide insufficient detail in the proxy, particularly on "hurdle height." The critical performance levels, such as threshold, target, and ceiling, are crucial in identifying the functional form of the $\mathrm{p}-\mathrm{v}$ provisions so that one can then discern value, deltas, and vegas of the grant. One concern is that the results in Sections 8 and 9 are contaminated by selection bias. For example, perhaps firms making very large, potentially conspicuous $\mathrm{p}-\mathrm{v}$ awards do not disclose details of the awards. We perform a logit analysis of firms that disclose hurdle height versus those that do not. The Post-2005 dummy is positive and significant, which is consistent with the enhanced reporting requirements promulgated around the same time as FAS 123R. Stock return volatility and

\footnotetext{
${ }^{30}$ We test robustness of our results by examining first-time usage of a p-v provision. By and large, the results are consistent with those in Table 10. The Post-2005 and New-CEO indicators are positive and significant and stock-return volatility is negative and significant, though firm size, prior firm performance, and number of business segments tend not to have much explanatory power. We also divide the sample into observations during 1998-2005 and 2006-2012. The New-CEO indicator is important in the earlier period but less so after 2005. This is true for coefficients on a number of other variables and is likely to be due to the diminished sample size.
} 
industry adoption are positively related to the tendency to disclose, but little else differs among disclosers and non-disclosers. These results likely reduce concerns about selection bias.

\section{The Effects of PV Provisions on Firm Risk (and Performance)}

The connection between contract design for the management team and firm performance and risk is a substantial and consistently-active portion of the literature in empirical corporate finance. ${ }^{31}$ Accordingly, we examine the relation between usage of $\mathrm{p}-\mathrm{v}$ versus $\mathrm{t}-\mathrm{v}$ provisions and subsequent stock and accounting performance, firm risk, and investment and financial policy.

Table 12 reports the results of difference-in-differences experiments. The sample of $\mathrm{p}-\mathrm{v}$ firms is explained in Table 1. We select yearly control firms by matching non-p-v firms with p-v firms on size (measured by market value of equity) and industry (defined as 2-digit SIC code). We regress performance, risk, and policy measures on $P V$, Post, and $P V^{*}$ Post. $P V$ takes the value one if the firm uses p-v provisions, and zero otherwise. Post takes the value one if the year follows the fiscal year of the grant of $\mathrm{p}-\mathrm{v}$ awards (Years $+1,+2,+3$ ), and zero if the year precedes the $\mathrm{p}-\mathrm{v}$ grant (Year -1$)$. Year 0 is the fiscal year of grant of the p-v awards. The other variables are defined in Table 10.

The results in Table 12 indicate that both accounting and market performance are greater two and three years beyond usage of performance conditions, all else equal. The estimated coefficients on $P V^{*}$ Post are positive and statistically significant. The same results hold for firm risk. The volatility of stock returns is significantly elevated two and three years after a p-v award.

\footnotetext{
${ }^{31}$ Early contributions to the literature that examines performance as a function of compensation structure include Morck, Shleifer, and Vishny (1988) and McConnell and Servaes (1990). Numerous others investigate the ownershipperformance relation using different data, various measures of performance and ownership structure, and alternative empirical methods. See Demsetz and Lehn (1985), Kole (1997), Himmelberg, Hubbard, and Palia (1999), Demsetz and Villalonga (2001), Palia (2001), and Claessens, Djankov, Fan, and Lang (2002), Coles, Lemmon, and Meschke (2012), and Coles Lemmon and Wang (2011), among others. For contributions to the literature on contract design and firm risk, investment policy, and financial policy, see Coles, Daniel, and Naveen (2006), Cohen, Hall, and Viceira (2000), Rajgopal and Shevlin (2002), and Guay (1999).
} 
While these results are striking, our attempts to identify the mechanisms for abnormally high performance and firm risk are not successful. As Table 12 reports, on average there appears to be no change in investment policy (R\&D intensity, investment) or financial policy (leverage) following the $\mathrm{p}-\mathrm{v}$ award that would generate abnormally high firm accounting or stock performance or firm risk.

\section{Conclusion}

Just as stock grants are replacing option awards, performance-vesting provisions are displacing traditional vesting schedules, and $\mathrm{p}-\mathrm{v}$ accounting hurdles are replacing $\mathrm{p}-\mathrm{v}$ stock price hurdles. The scale of usage documented in our sample proves correct the conjecture in GIL (2007) and BBCK (2010), based on early usage and correspondingly modest samples of rudimentary, all-ornone provisions, that p-v provisions would become increasingly complex and ubiquitous.

We delineate the payoff structure for the executive as a function of potential ex post realizations of the performance metrics on which the p-v conditions rely. Because of the difficulty of constructing a risk-free hedge, we develop and apply a risk-adjusted approach to measure the value and incentive characteristics of $\mathrm{p}-\mathrm{v}$ grants of stock and options. The value of $\mathrm{p}-\mathrm{v}$ grants often depends both directly and indirectly (through accounting performance metrics) on stock price, so we develop and estimate new measures of executive incentives to enhance shareholder wealth and influence firm risk. These new approaches are particularly relevant given the trends in practice away from options towards stock as the back-end asset, away from time-based and accelerated-vesting towards conditional vesting, and towards the use of accounting hurdles in conjunction with or instead of stock price hurdles.

Our ex ante simulations predict that the vesting targets of awards with single accounting metrics or share price will be surmounted about 40 percent of the time, which is very close to the 
actual ex post hit rate. Accommodating correlation between the accounting performance metric and stock price and the relation between the vesting function and the value of the back-end instrument, the grant date value of the typical grant is significantly lower, on average $39 \%$ lower, than if the option or stock grant were unencumbered by the $\mathrm{p}-\mathrm{v}$ provision. Moreover, for $\mathrm{p}-\mathrm{v}$ grants based on a single accounting metric, since 2006 on average firms disclose a value that is $19 \%$ higher than the value we calculate, while for $\mathrm{p}-\mathrm{v}$ grants contingent on stock price, on average firms underreport value by $20 \%$.

We estimate traditional measures of executive incentives as well as aggregate measures that include incentives that flow through the dependence of grant value on accounting performance and find that p-v provisions significantly amplify the incentives of executives to advance shareholder interests and take risk. Scaling the size of the $\mathrm{p}-\mathrm{v}$ grant to be equal in value to the grant of stock or options had there been no p-v provision, on average conventionally defined (marginal) delta (in stock price) is approximately 33\% larger on average, while mean aggregate delta is 75\% larger. Average aggregate vega is $474 \%$ larger than it would be, holding grant value constant, if measured without regard for the p-v provision, while aggregate vega of a value-neutral p-v grant is nearly 22 times that of the value-comparable grant non-p-v grant.

We characterize and explain cross-sectional and time-series usage patterns of p-v provisions and choice of performance metric and isolate the causes and consequences of changing usage patterns. The propensity to use a p-v provision and base that provision on accounting performance is strongly related to implementation of accounting changes in 2005. We also find that the use of performance vesting over time vesting is strongly, positively related to firm size, to the firm engaging a compensation consultant, especially a consultant with significant market share, to formulate compensation, and to CEO turnover. These first two results are consistent with our 
hypotheses concerning economies of scale in sophisticated contract design and the notion that compensation consultants are both employed and disposed to design and implement complex executive compensation contracts. The third result is consistent with the notion that $\mathrm{p}-\mathrm{v}$ provisions can be a way for the firm not to convey stock or options to a departing CEO who has been discovered (e.g., from poor firm performance) to be a poor match for the firm (see BBCK, 2010) and with the empirical observation that the rate of CEO turnover is increasing through time (Kaplan and Minton, 2012). Usage of performance vesting rather than time vesting is positively related to number of business segments, $\mathrm{p}-\mathrm{v}$ usage in the industry, board size, board independence, and board interlocks and negatively associated with volatility of firm stock return and CEO ownership. Conditional on use of performance vesting, there is a strong trend towards using accounting hurdles rather than stock-price triggers. In the data on hurdles we observe a wide spectrum of accounting measures, and a wide spectrum of triggers that are based neither on stock price nor on accounting numbers. The reason, in part, is likely to be more flexible reporting requirements for grants that depend on something other than stock price. Indeed, the logit analysis of type of p-v target identifies a positive and significant relation between the rule changes and usage of an accounting hurdle.

We document the association between usage of performance vesting and firm risk, performance, and policy. Using a p-v provision is associated with a significant subsequent increase in stock performance, accounting performance (ROA), and firm risk. While these results are striking, our experimental attempts to identify the mechanisms of these changes are not successful. To be specific, on average there appears to be no associated change in investment policy (R\&D intensity, investment) or financial policy (leverage).

Overall, one consequence of the complexity associated with $\mathrm{p}-\mathrm{v}$ provisions is significant error in measurement of the primary characteristics of executive compensation. Measurement that is 
correct is likely to be useful to individual and institutional investors, corporations, executives, compensation consultants, regulators (SEC, FASB), and policymakers. Additionally, failure to account for how p-v provisions affect incentives could lead to measurement error, misspecified empirical designs, spurious results, and incorrect interpretations of results in academic research. 


\section{References}

Anderson, J., Core, J., 2013. Managerial incentives to increase firm volatility provided by debt, stock, and options, working paper, Masschusetts Institute of Technology.

Babenko, I., B. Bennett, J. Bizjak, and J. Coles, 2012. Clawback provisions, working paper, Arizona State University.

Bennett, B., Bettis, J., Gopalan, R., and T. Milbourn, 2013. Performance contingent pay, working paper, Washington University in St. Louis.

Bettis, C., Bizjak, J., Coles, J., Kalpathy, S., 2010. Stock and option grants with performance-based vesting provisions, Review of Financial Studies 23, 3849-3888.

Bettis, C., Bizjak, J., Coles, J., Young, B., 2012, Do firms behave opportunistically when expensing equity awards, working paper, TCU.

Bettis, C., Bizjak, J., Coles, J., Young, B., 2013, Explicit relative performance contracts for executives, working paper, Arizona State University.

Bettis, J., Bizjak, J. and M. Lemmon, 2005. Exercise behavior and the value and incentives of employee stock options. Journal of Financial Economics 76, 445-470.

Bettis, J., J. Bizjak, and S. Kalpathy, 2011. Insiders’ use of hedging instruments: An empirical examination, unpublished manuscript, Texas Christian University.

Bizjak, J., S. Kalpathy, and R. Thompson, 2013. Modeling equity compensation with accounting contingencies, working paper, Southern Methodist University.

Bizjak, J., Lemmon, M., and T. Nguyen, 2011. Are all CEOs above average? An empirical analysis of compensation peer groups and pay design. Journal of Financial Economics 100, 538-555.

Black, F., and M. Scholes, 1973. The pricing of options and corporate liabilities. The Journal of Political Economy 81, 637-654.

Cadman, B., T. Rusticus, and J. Sunder, 2013. Stock option grant vesting terms: economic and financial reporting determinants. Review of Accounting Studies 18, 1159-1190.

Camara, A., Henderson, V., 2009. Performance based compensation and direct earnings management, working paper, Oklahoma State University and University of Oxford.

Carter, M., Ittner, C., Zechman, S., 2009. Explicit relative performance evaluation in performancevested equity grants. Review of Accounting Studies, 14, 269-306.

Chen, M., D. Greene, and J. Owers, 2012. Clawback provisions in executive compensation, working paper, Georgia State University. 
Claessens, S., Djankov, S., Fan, J., Lang, L., 2002. Disentangling the incentive and entrenchment effect of large shareholdings. The Journal of Finance, 57, 2741-2771.

Cohen, R., Hall, B., Viceira, L., 2000. Do executive stock options encourage risk-taking? Working Paper. Harvard Business School.

Coles, J., Daniel, N., Naveen, L., 2006, Executive compensation and managerial risk-taking. Journal of Financial Economics 79, 431-468.

Coles, J., M. Lemmon, J. Meschke, 2012. Structural Models and Endogeneity in Corporate Finance, Journal of Financial Economics 103, 149-168.

Coles, J., M. Lemmon, Y. Wang, 2011. The joint determinants of managerial ownership, board independence, and firm performance, working paper, Arizona State University.

Conyon, M., 2000, Peck, S., Read, L., Sadler, G., 2000. The structure of executive compensation contracts: UK evidence. Long Range Planning 33, 478-503.

Core, J., Guay, W., 2002. Estimating the value of employee stock option portfolios and their sensitivities to price and volatility. Journal of Accounting Research 40, 613-630.

Demsetz, H., Lehn, K., 1985. The structure of corporate ownership: Causes and consequences. Journal of Political Economy 93, 1155-77.

Demsetz, H., Villalonga, B., 2001. Ownership structure and corporate finance. Journal of Corporate Finance 7, 209-33.

Edmans, A., Gabaix, X., and A. Landier., 2009. A multiplicative model of optimal CEO incentives in market equilibrium, Review of Financial Studies 22, 4881-917.

Fernandes, N., Ferreira, M., Matos, P., and K. J. Murphy, 2013. Are U.S. CEOs paid more? New international evidence, Review of Financial Studies 26, 323-367.

Financial Accounting Standards Board. Accounting for stock based compensation no. 123. October 1995.

Financial Accounting Standards Board. Statement of financial accounting standards no. 123 (revised 2004): share-based payment. December 2004.

Frydman, C., D. Jenter, 2010. CEO compensation, working paper, Stanford University.

Gerakos, J., Ittner, C., Larcker, D., 2007. The structure of performance-vested stock option grants. In: Antle, R., Liang, P., Gjesdahl, F. (Eds.). Essays on accounting theory in honour of Joel S. Demski. Springer. 
Guay, W., 1999. The sensitivity of CEO wealth to equity risk: An analysis of the magnitude and determinants. Journal of Financial Economics 53, 43-71.

Hayes, R., Lemmon, M., Qiu, M., 2012. Stock option and managerial incentives for risk-taking: Evidence from FAS 123R. Journal of Financial Economics 105, 174-190.

Himmelberg, C., Hubbard, R., Palia, D., 1999. Understanding the determinants of managerial ownership and the link between ownership and performance. Journal of Financial Economics 53, 353-84.

Holden, C., and D. Kim, 2013, Performance share plans: valuation, optimal design, and empirical tests, working paper, Indiana University.

Holmstrom, B., 1979. Moral hazard and observability, The Bell Journal of Economics 10, 74-91.

Jensen, M. and K. Murphy, 1990. Performance pay and top-management incentives, Journal of Political Economy 98, 225-264.

Johnson, S., Tian, Y., 2000. The value and incentive effects of nontraditional executive stock option plans. Journal of Financial Economics 57, 3-34.

Kaplan, S. N. and Minton, B. A., 2012. How has CEO turnover changed?. International Review of Finance 12, 57-87.

Kole, S., 1997. The complexity of compensation contracts. Journal of Financial Economics 43, 79104.

Kuang, Y., 2008, Performance-vested stock options and earnings management. Journal of Business, Finance and Accounting 35, 1049-1078.

Kuang, Y., Suijs, J., 2006. Incentive effects of performance-vested stock options. Working paper, Tilburg University.

McConnell, J., Servaes, H., 1990. Additional evidence on equity ownership and corporate value. Journal of Financial Economics 27, 595-612.

Morck, R., Shleifer, A., Vishny, R., 1988. Management ownership and market valuation. Journal of Financial Economics 20, 293-315.

Murphy, K., and M. Jensen, 2011. CEO bonus plans: And how to fix them, working paper, University of Southern California.

Palia, D., 2001. The endogeneity of managerial compensation in firm valuation: A solution. Review of Financial Studies 14, 735-64. 
Rajgopal, S. and T. Shevlin, 2002, Empirical evidence on the relation between stock option compensation and risk taking, Journal of Accounting and Economics, 33, 145-171. 


\section{Figure 1: L3 Communications 2008 Grant of Stock With Conditional Vesting Provision to CEO}

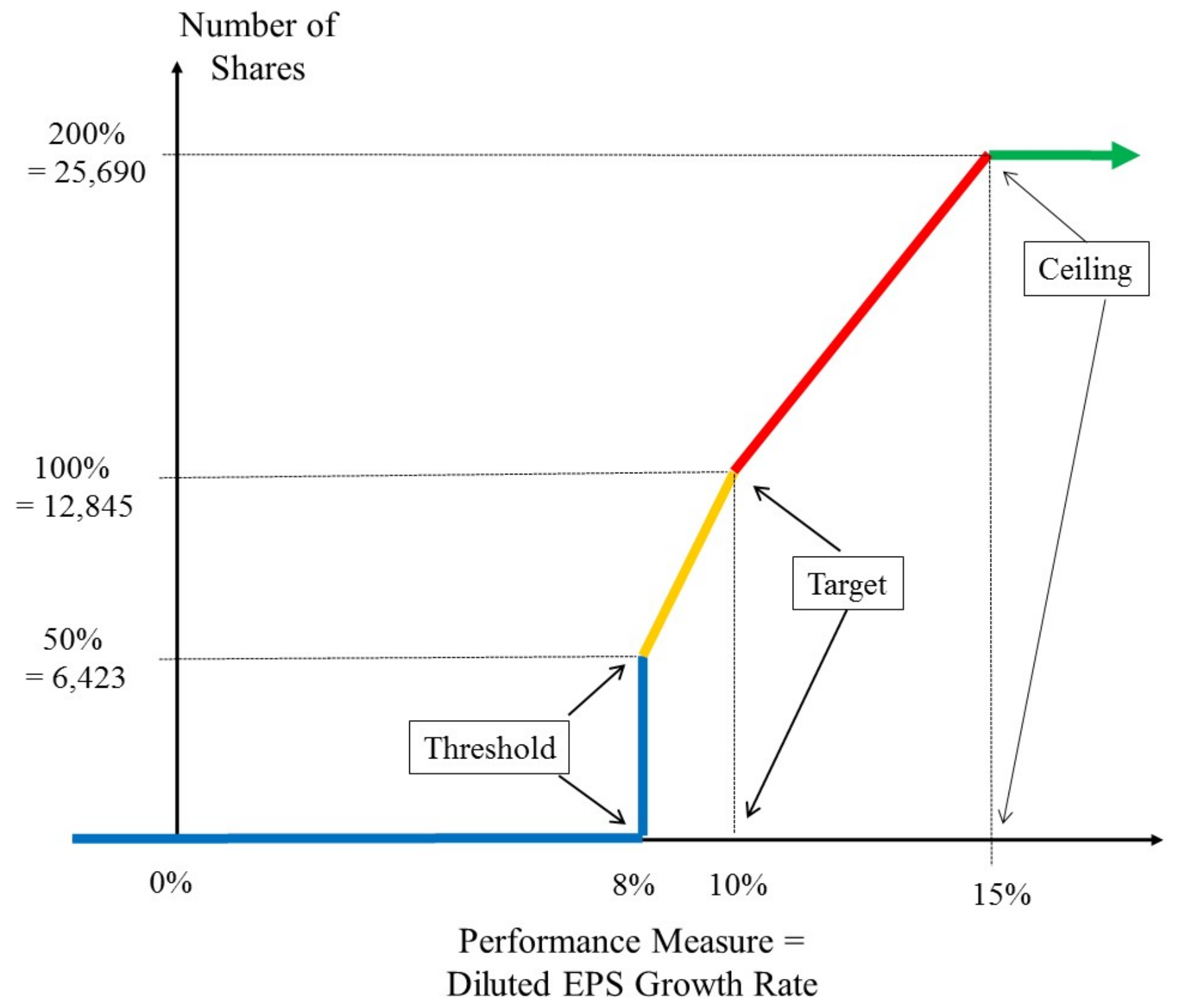




\section{Figure 2: Amgen 2008 Grant of Stock With Conditional Vesting Provision to CEO}

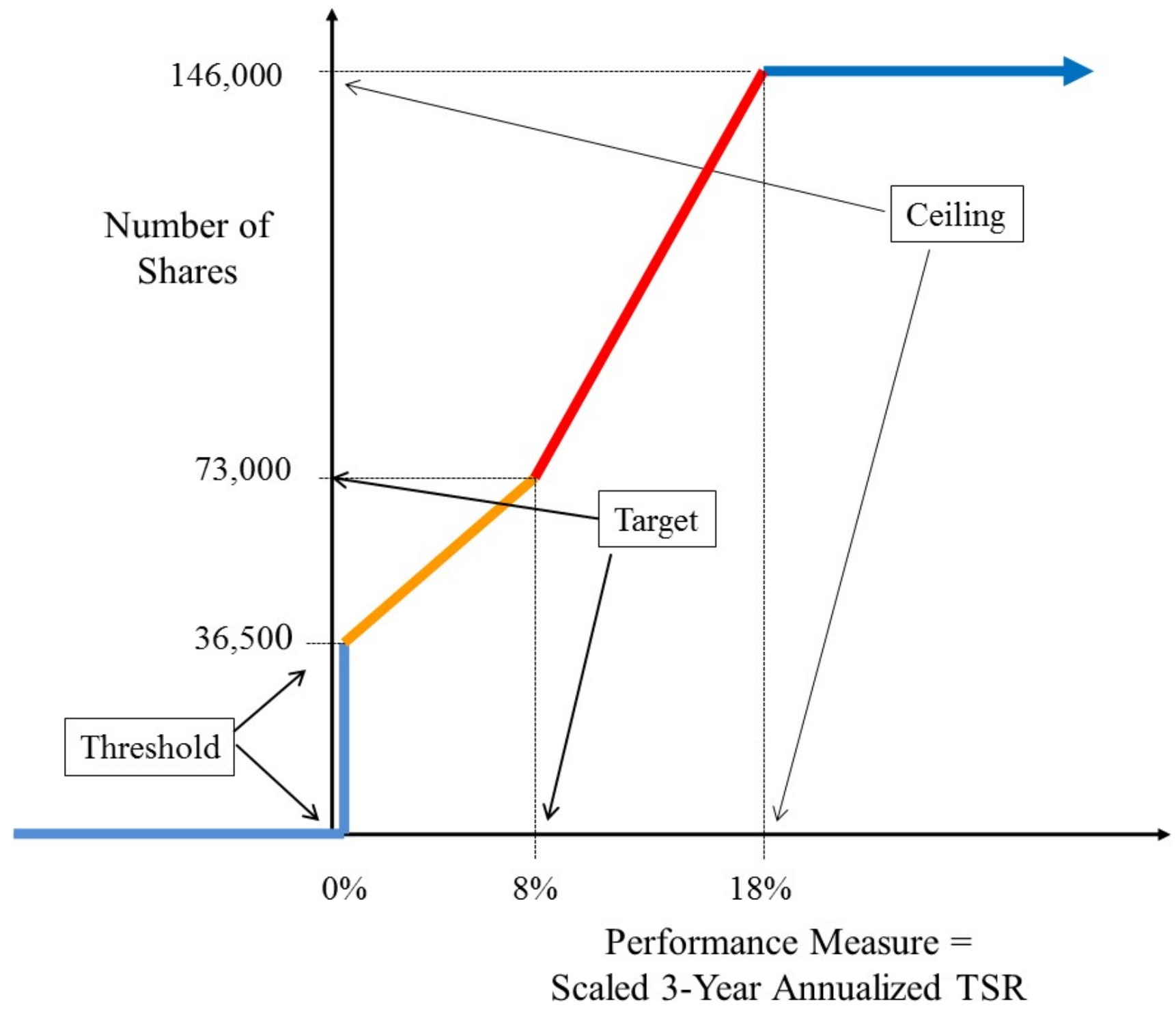




\section{Figure 3: Ex Post Value of Amgen 2008 Grant of Stock With Conditional Vesting Provision to CEO}

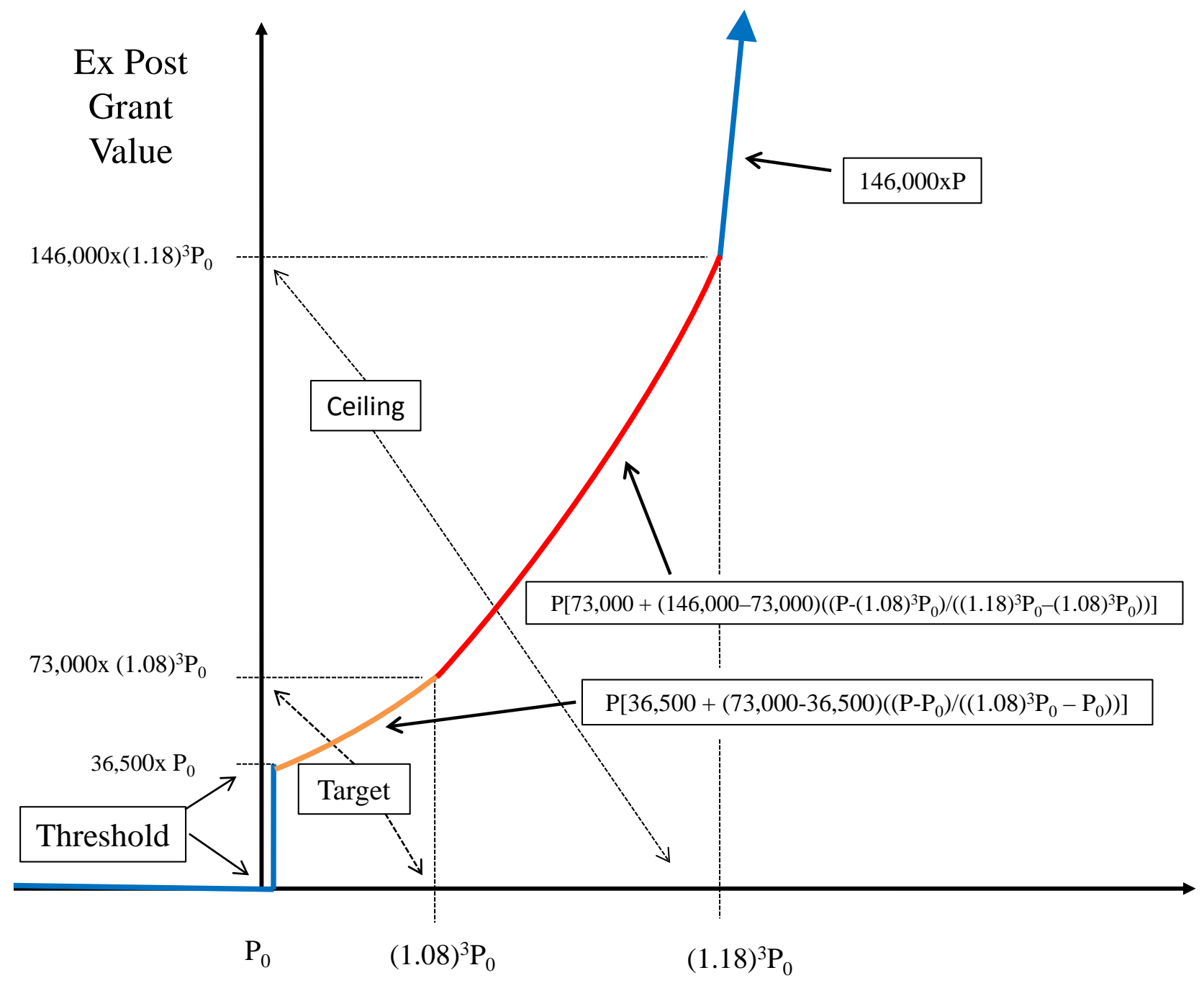

Stock Price Relative to Initial Stock Price $\left(\mathrm{P}_{0}\right)$ 
Figure 4: Usage Rates for Large US Firms of Time-vesting and Performance-vesting Grants of Stock and Options to Executives

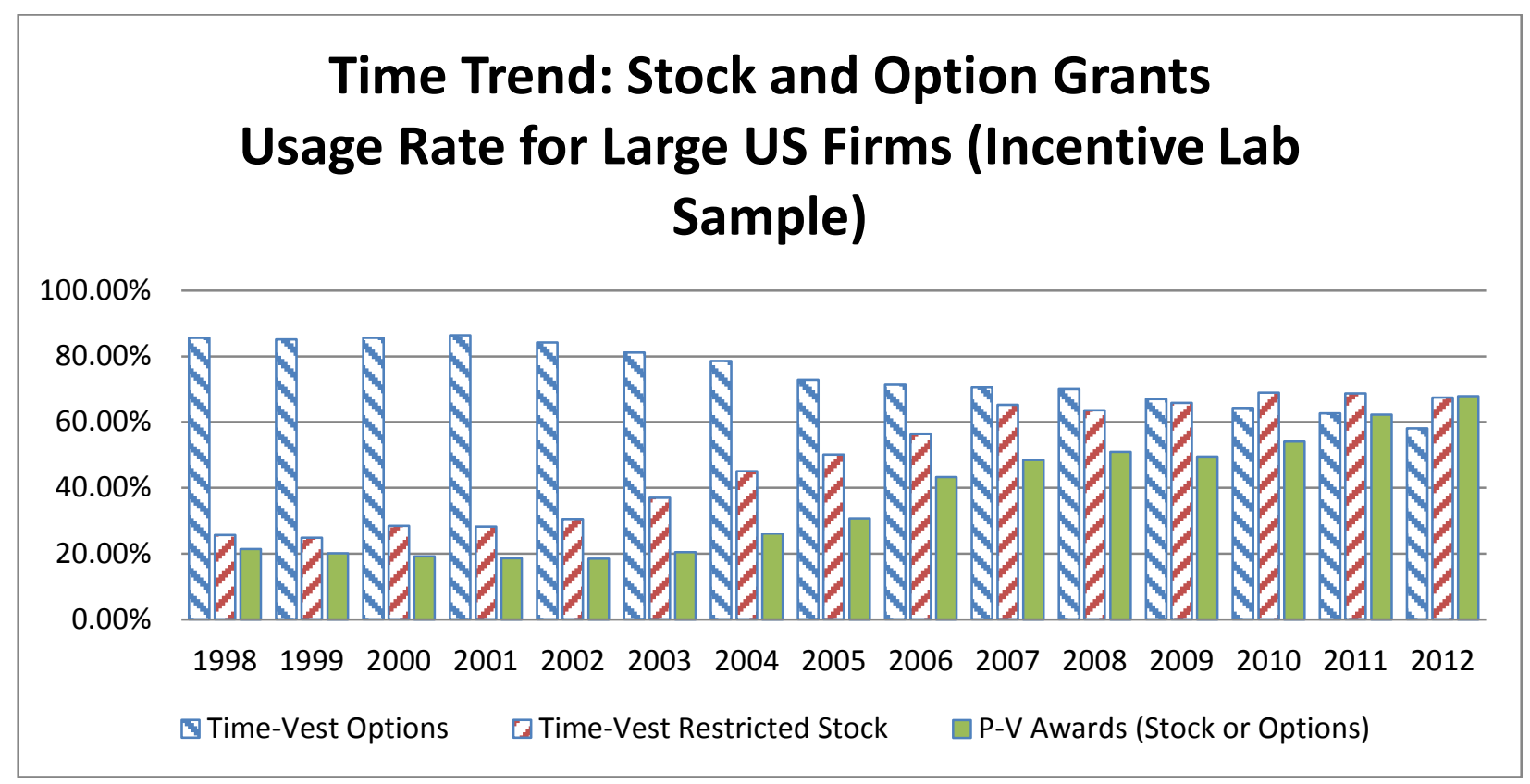


Figure 5: Time Series around FAS 123R (2005) of Aggregate Vega Arising from Grants of Time-vesting and Performance vesting Grants of Stock and Options to Executives

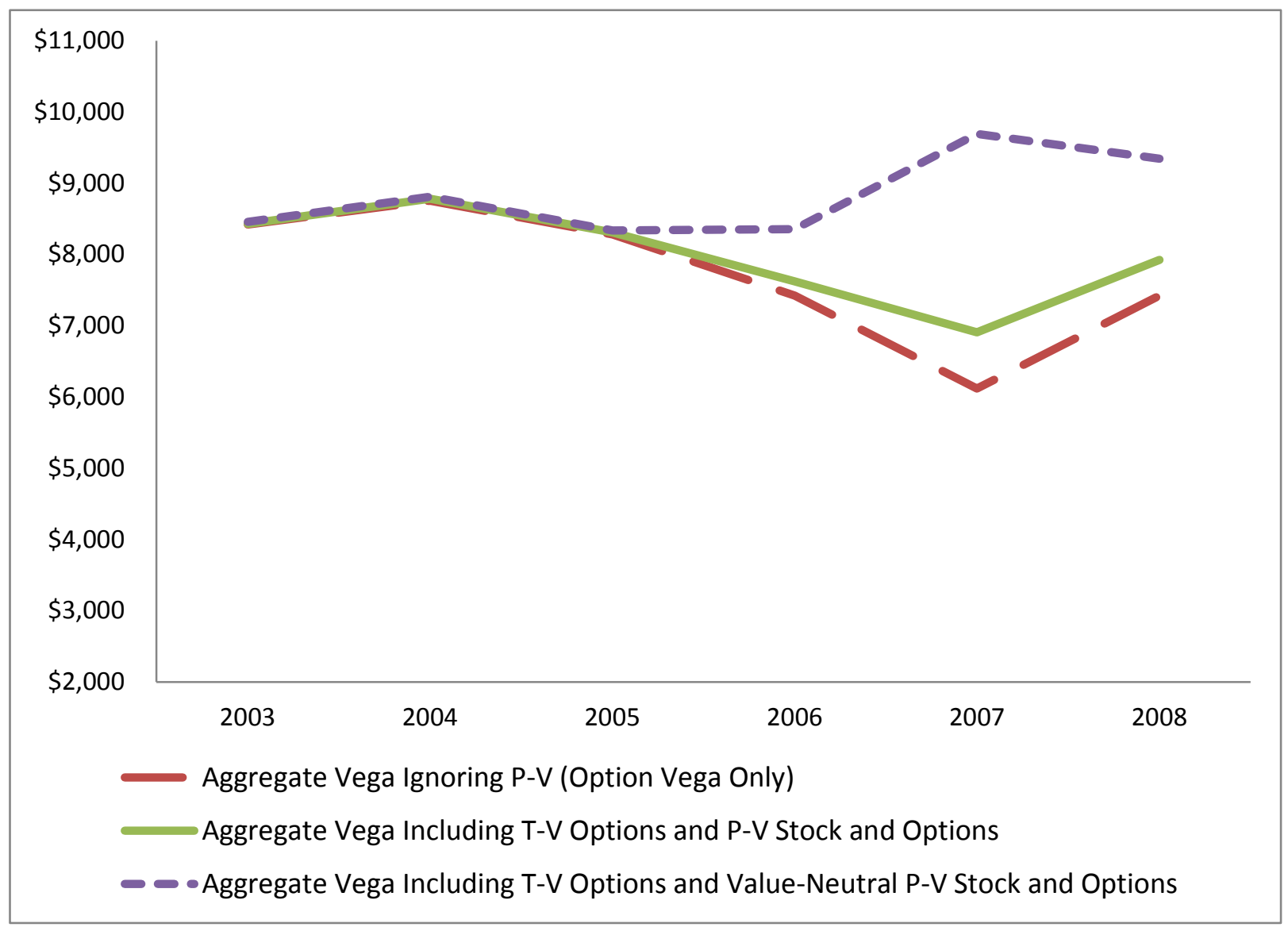




\section{Table 1: Performance-based and time-based vesting equity awards to executives (NEOs)}

The table reports the distribution of firm-years that comprise our sample. The full sample consists of 1,833 firms during the period between 1998 and 2012. The sample includes 1,268 firms that tie vesting of stock or stock options to stock price, accounting, or other non-financial performance metrics ("performance-based awards") and 1,793 firms that tie vesting of stock or stock options to passage of time ("time-based awards"). Reported value of stock or stock option awards is the grant- date fair value of awards disclosed in proxy statements under the new compensation disclosure rules of 2006. For the period prior to the new compensation disclosure rules, we use the value of stock or stock option awards disclosed by firms in their annual proxy statements and where values are missing we use Black-Scholes model to value stock option awards, and stock price during the grant year to value stock awards. To compute the ratio we add all performance-based and time-based awards across all executives for a firm in a given fiscal year.

\begin{tabular}{|c|c|c|c|c|c|c|c|c|}
\hline \multirow[t]{2}{*}{ Year } & \multicolumn{2}{|c|}{ Time-based awards } & \multicolumn{2}{|c|}{$\begin{array}{c}\text { Performance-based } \\
\text { awards }\end{array}$} & \multirow{2}{*}{$\begin{array}{l}\text { Time-based } \\
\text { awards: } \\
\text { Stock or } \\
\text { Options } \\
\text { [N=17,067] }\end{array}$} & \multirow{2}{*}{$\begin{array}{c}\text { Performance- } \\
\text { based awards: } \\
\text { Stock or } \\
\text { Options } \\
\\
\mathrm{N}=6,967]\end{array}$} & \multirow{2}{*}{$\begin{array}{c}\text { Reported value of all } \\
\text { performance-based } \\
\text { awards/Sum of reported } \\
\text { values of all } \\
\text { performance- and time- } \\
\text { based awards } \\
\text { [N=17,838] }\end{array}$} & \multirow{2}{*}{$\begin{array}{c}\begin{array}{c}\text { Sample } \\
\text { Firms }\end{array} \\
{[\mathrm{N}=19,529]}\end{array}$} \\
\hline & $\begin{array}{c}\text { Option } \\
{[\mathrm{N}=14,735]}\end{array}$ & $\begin{array}{c}\text { Stock } \\
{[\mathrm{N}=9,253]}\end{array}$ & $\begin{array}{c}\text { Option } \\
{[\mathrm{N}=1,019]}\end{array}$ & $\begin{array}{c}\text { Stock } \\
{[\mathrm{N}=6,325]}\end{array}$ & & & & \\
\hline 2000 & 1,200 & 398 & 99 & 193 & 1,253 & 268 & $9 \%$ & 1,403 \\
\hline 2001 & 1,197 & 390 & 77 & 196 & 1,240 & 258 & $9 \%$ & 1,386 \\
\hline 2002 & 1,169 & 424 & 59 & 212 & 1,231 & 256 & $9 \%$ & 1,388 \\
\hline 2003 & 1,115 & 508 & 48 & 245 & 1,201 & 281 & $12 \%$ & 1,374 \\
\hline 2004 & 1,076 & 616 & 53 & 318 & 1,195 & 357 & $15 \%$ & 1,369 \\
\hline 2005 & 980 & 673 & 54 & 377 & 1,145 & 413 & $18 \%$ & 1,345 \\
\hline 2010 & 776 & 832 & 45 & 635 & 1,064 & 654 & $32 \%$ & 1,207 \\
\hline 2011 & 736 & 807 & 59 & 705 & 1,024 & 731 & $36 \%$ & 1,175 \\
\hline 2012 & 655 & 760 & 60 & 743 & 957 & 766 & $41 \%$ & 1,128 \\
\hline
\end{tabular}


Table 2: Performance-based vesting equity awards to executives

The table provides details of the distribution of performance-based awards. The full sample consists of 1,833 firms during the period between 1998 and 2012. Of these, 1,268 firms at least once tie vesting of stock or stock options to stock price, accounting, or other non-financial performance metrics ("performance-based awards") and 1,793 firms tie at least once vesting of stock or stock options to passage of time ("time-based awards"). Row or column numbers may not always total to $\mathrm{N}$ because some firms use more than one type of vesting provision.

Panel A: Year-wise distribution of grants

\begin{tabular}{|c|c|c|c|c|}
\hline \multirow{3}{*}{ Year } & \multicolumn{2}{|c|}{$\begin{array}{c}\text { Grant: Options } \\
{[\mathrm{N}=1,019]} \\
\end{array}$} & \multicolumn{2}{|c|}{$\begin{array}{c}\text { Grant: Restricted stock } \\
{[\mathrm{N}=6,325]}\end{array}$} \\
\hline & \multicolumn{2}{|c|}{ Performance-based Vesting Provision } & \multicolumn{2}{|c|}{ Performance-based Vesting Provision } \\
\hline & $\begin{array}{c}\text { Accelerated } \\
{[\mathrm{N}=480]}\end{array}$ & $\begin{array}{r}\text { Contingent } \\
{[N=580]}\end{array}$ & $\begin{array}{c}\text { Accelerated } \\
{[\mathrm{N}=425]}\end{array}$ & $\begin{array}{c}\text { Contingent } \\
{[\mathrm{N}=6,018]}\end{array}$ \\
\hline 1998 & 62 & 34 & 20 & 186 \\
\hline 1999 & 80 & 34 & 24 & 181 \\
\hline 2000 & 70 & 34 & 26 & 171 \\
\hline 2001 & 60 & 19 & 26 & 177 \\
\hline 2002 & 45 & 14 & 39 & 177 \\
\hline 2003 & 34 & 15 & 42 & 208 \\
\hline 2004 & 41 & 13 & 52 & 275 \\
\hline 2005 & 29 & 30 & 44 & 343 \\
\hline 2006 & 17 & 54 & 33 & 512 \\
\hline 2007 & 12 & 54 & 35 & 565 \\
\hline 2008 & 12 & 53 & 33 & 587 \\
\hline 2009 & 12 & 66 & 16 & 569 \\
\hline 2010 & 11 & 43 & 10 & 630 \\
\hline 2011 & 3 & 58 & 16 & 698 \\
\hline 2012 & 1 & 59 & 9 & 739 \\
\hline
\end{tabular}

Panel B: Distribution of performance measures for contingent vesting awards

\begin{tabular}{ccccc}
\hline Year & $\begin{array}{c}\text { N } \\
\text { Firms with } \\
\text { any PV }\end{array}$ & Accounting & Stock Price & Other \\
\hline 1998 & 209 & $57.9 \%$ & $53.1 \%$ & $17.7 \%$ \\
1999 & 204 & $55.4 \%$ & $51.5 \%$ & $15.2 \%$ \\
2000 & 192 & $55.2 \%$ & $55.7 \%$ & $17.2 \%$ \\
2001 & 187 & $61.5 \%$ & $49.2 \%$ & $17.1 \%$ \\
2002 & 185 & $59.5 \%$ & $55.7 \%$ & $16.8 \%$ \\
2003 & 217 & $65.4 \%$ & $51.6 \%$ & $13.8 \%$ \\
2004 & 281 & $67.6 \%$ & $45.6 \%$ & $16.0 \%$ \\
2005 & 363 & $73.0 \%$ & $41.6 \%$ & $15.2 \%$ \\
2006 & 530 & $78.7 \%$ & $33.4 \%$ & $15.1 \%$ \\
2007 & 588 & $79.1 \%$ & $36.1 \%$ & $13.9 \%$ \\
2008 & 615 & $80.3 \%$ & $36.9 \%$ & $13.8 \%$ \\
2009 & 591 & $77.5 \%$ & $37.6 \%$ & $14.6 \%$ \\
2010 & 649 & $78.1 \%$ & $38.8 \%$ & $13.3 \%$ \\
2011 & 723 & $76.3 \%$ & $43.0 \%$ & $14.1 \%$ \\
2012 & 760 & $75.4 \%$ & $48.0 \%$ & $12.4 \%$ \\
\hline
\end{tabular}


Panel C: Distribution of accounting metrics for contingent vesting awards

\begin{tabular}{|c|c|c|c|c|c|c|c|c|c|c|c|}
\hline & 1998 & 1999 & 2000 & 2001 & 2002 & 2003 & 2004 & 2005 & 2006 & 2007 & 2008 \\
\hline $\mathrm{N}$ & 121 & 113 & 106 & 115 & 110 & 142 & 190 & 265 & 417 & 465 & 494 \\
\hline Earnings & $64.5 \%$ & $57.5 \%$ & $69.8 \%$ & $64.3 \%$ & $60.9 \%$ & $57.7 \%$ & $51.1 \%$ & $58.1 \%$ & $61.6 \%$ & $64.7 \%$ & $65.2 \%$ \\
\hline Sales & $10.7 \%$ & $10.6 \%$ & $7.5 \%$ & $9.6 \%$ & $13.6 \%$ & $9.2 \%$ & $12.6 \%$ & $14.0 \%$ & $20.1 \%$ & $22.6 \%$ & $22.7 \%$ \\
\hline Profit Margin & $2.5 \%$ & $1.8 \%$ & $1.9 \%$ & $0.0 \%$ & $0.0 \%$ & $2.1 \%$ & $2.1 \%$ & $3.4 \%$ & $4.1 \%$ & $5.6 \%$ & $6.5 \%$ \\
\hline ROA & $5.0 \%$ & $8.8 \%$ & $3.8 \%$ & $6.1 \%$ & $7.3 \%$ & $4.9 \%$ & $5.3 \%$ & $4.5 \%$ & $3.4 \%$ & $3.4 \%$ & $1.6 \%$ \\
\hline ROE & $19.0 \%$ & $14.2 \%$ & $17.0 \%$ & $14.8 \%$ & $11.8 \%$ & $12.0 \%$ & $10.5 \%$ & $10.2 \%$ & $9.6 \%$ & $11.8 \%$ & $8.1 \%$ \\
\hline ROI & $14.0 \%$ & $12.4 \%$ & $12.3 \%$ & $20.0 \%$ & $19.1 \%$ & $19.0 \%$ & $22.6 \%$ & $19.2 \%$ & $18.2 \%$ & $17.6 \%$ & $18.2 \%$ \\
\hline Cashflow & $5.8 \%$ & $7.1 \%$ & $4.7 \%$ & $7.0 \%$ & $11.8 \%$ & $13.4 \%$ & $13.2 \%$ & $13.6 \%$ & $12.5 \%$ & $13.1 \%$ & $12.6 \%$ \\
\hline EVA & $9.1 \%$ & $11.5 \%$ & $8.5 \%$ & $9.6 \%$ & $3.6 \%$ & $4.2 \%$ & $5.3 \%$ & $4.2 \%$ & $4.1 \%$ & $3.0 \%$ & $3.8 \%$ \\
\hline Other & $9.1 \%$ & $13.3 \%$ & $9.4 \%$ & $12.2 \%$ & $14.5 \%$ & $16.9 \%$ & $11.6 \%$ & $12.5 \%$ & $14.4 \%$ & $16.1 \%$ & $16.0 \%$ \\
\hline Vague & $1.7 \%$ & $2.7 \%$ & $1.9 \%$ & $2.6 \%$ & $2.7 \%$ & $5.6 \%$ & $6.3 \%$ & $1.9 \%$ & $0.7 \%$ & $0.4 \%$ & $0.6 \%$ \\
\hline
\end{tabular}

Panel C [contd.]: Distribution of accounting metrics for contingent vesting awards

\begin{tabular}{lcccc}
\hline & 2009 & 2010 & 2011 & 2012 \\
\hline $\mathrm{N}$ & 458 & 507 & 552 & 573 \\
Earnings & $66.8 \%$ & $65.3 \%$ & $64.1 \%$ & $62.1 \%$ \\
Sales & $22.1 \%$ & $23.1 \%$ & $25.7 \%$ & $24.1 \%$ \\
Profit Margin & $5.0 \%$ & $7.3 \%$ & $6.7 \%$ & $6.5 \%$ \\
ROA & $2.6 \%$ & $2.2 \%$ & $2.9 \%$ & $4.2 \%$ \\
ROE & $7.4 \%$ & $8.3 \%$ & $7.6 \%$ & $8.0 \%$ \\
ROI & $15.3 \%$ & $16.2 \%$ & $16.1 \%$ & $17.6 \%$ \\
Cashflow & $13.8 \%$ & $14.4 \%$ & $12.5 \%$ & $11.3 \%$ \\
EVA & $2.2 \%$ & $2.8 \%$ & $2.4 \%$ & $1.6 \%$ \\
Other & $16.8 \%$ & $17.8 \%$ & $17.4 \%$ & $16.6 \%$ \\
Vague & $0.4 \%$ & $0.8 \%$ & $0.5 \%$ & $0.9 \%$ \\
\hline
\end{tabular}

Panel D: Distribution of "other" metrics for contingent vesting awards

\begin{tabular}{lccccccccccc}
\hline & 1998 & 1999 & 2000 & 2001 & 2002 & 2003 & 2004 & 2005 & 2006 & 2007 & 2008 \\
\hline $\mathrm{N}$ & 37 & 31 & 33 & 32 & 31 & 30 & 45 & 55 & 80 & 82 & 85 \\
Business Unit & $5.4 \%$ & $0.0 \%$ & $3.0 \%$ & $0.0 \%$ & $3.2 \%$ & $3.3 \%$ & $2.2 \%$ & $1.8 \%$ & $2.5 \%$ & $1.2 \%$ & $5.9 \%$ \\
Customer & $10.8 \%$ & $6.5 \%$ & $3.0 \%$ & $3.1 \%$ & $3.2 \%$ & $3.3 \%$ & $4.4 \%$ & $5.5 \%$ & $5.0 \%$ & $1.2 \%$ & $4.7 \%$ \\
Debt & $0.0 \%$ & $0.0 \%$ & $0.0 \%$ & $0.0 \%$ & $0.0 \%$ & $0.0 \%$ & $0.0 \%$ & $0.0 \%$ & $1.3 \%$ & $0.0 \%$ & $1.2 \%$ \\
FDA & $0.0 \%$ & $0.0 \%$ & $0.0 \%$ & $0.0 \%$ & $0.0 \%$ & $0.0 \%$ & $0.0 \%$ & $0.0 \%$ & $0.0 \%$ & $1.2 \%$ & $0.0 \%$ \\
IPO & $0.0 \%$ & $0.0 \%$ & $3.0 \%$ & $0.0 \%$ & $0.0 \%$ & $0.0 \%$ & $0.0 \%$ & $0.0 \%$ & $0.0 \%$ & $1.2 \%$ & $0.0 \%$ \\
Individual & $27.0 \%$ & $25.8 \%$ & $24.2 \%$ & $15.6 \%$ & $19.4 \%$ & $23.3 \%$ & $13.3 \%$ & $16.4 \%$ & $27.5 \%$ & $25.6 \%$ & $20.0 \%$ \\
Operational & $5.4 \%$ & $3.2 \%$ & $15.2 \%$ & $12.5 \%$ & $25.8 \%$ & $16.7 \%$ & $6.7 \%$ & $9.1 \%$ & $13.8 \%$ & $12.2 \%$ & $11.8 \%$ \\
Same Store Sales & $0.0 \%$ & $0.0 \%$ & $0.0 \%$ & $3.1 \%$ & $3.2 \%$ & $0.0 \%$ & $0.0 \%$ & $0.0 \%$ & $3.8 \%$ & $3.7 \%$ & $4.7 \%$ \\
Other & $78.4 \%$ & $74.2 \%$ & $66.7 \%$ & $78.1 \%$ & $54.8 \%$ & $66.7 \%$ & $84.4 \%$ & $81.8 \%$ & $61.3 \%$ & $64.6 \%$ & $64.7 \%$ \\
Vague & $0.0 \%$ & $0.0 \%$ & $0.0 \%$ & $0.0 \%$ & $0.0 \%$ & $0.0 \%$ & $0.0 \%$ & $1.8 \%$ & $0.0 \%$ & $0.0 \%$ & $0.0 \%$ \\
\hline
\end{tabular}

Panel D [contd.]: Distribution of “other" metrics for contingent vesting awards

\begin{tabular}{lcccc}
\hline & 2009 & 2010 & 2011 & 2012 \\
\hline $\mathrm{N}$ & 86 & 86 & 102 & 94 \\
Business Unit & $2.3 \%$ & $3.5 \%$ & $2.9 \%$ & $3.2 \%$ \\
Customer & $2.3 \%$ & $3.5 \%$ & $4.9 \%$ & $4.3 \%$ \\
Debt & $1.2 \%$ & $2.3 \%$ & $2.0 \%$ & $0.0 \%$ \\
FDA & $1.2 \%$ & $0.0 \%$ & $1.0 \%$ & $0.0 \%$ \\
IPO & $1.2 \%$ & $1.2 \%$ & $0.0 \%$ & $0.0 \%$ \\
Individual & $18.6 \%$ & $20.9 \%$ & $13.7 \%$ & $12.8 \%$ \\
Operational & $9.3 \%$ & $10.5 \%$ & $9.8 \%$ & $8.5 \%$ \\
Same Store Sales & $2.3 \%$ & $1.2 \%$ & $3.9 \%$ & $3.2 \%$ \\
Other & $76.7 \%$ & $75.6 \%$ & $74.5 \%$ & $79.8 \%$ \\
Vague & $0.0 \%$ & $0.0 \%$ & $0.0 \%$ & $0.0 \%$ \\
\hline
\end{tabular}


Panel E: Distribution of performance goals for contingent vesting awards

\begin{tabular}{lccc}
\hline Year & N & Absolute & Relative \\
\hline 1998 & 209 & $81.3 \%$ & $38.8 \%$ \\
1999 & 204 & $77.5 \%$ & $35.8 \%$ \\
2000 & 192 & $79.2 \%$ & $40.1 \%$ \\
2001 & 187 & $79.1 \%$ & $36.9 \%$ \\
2002 & 185 & $71.9 \%$ & $48.1 \%$ \\
2003 & 217 & $67.7 \%$ & $50.2 \%$ \\
2004 & 281 & $74.0 \%$ & $46.3 \%$ \\
2005 & 363 & $79.9 \%$ & $40.2 \%$ \\
2006 & 530 & $84.0 \%$ & $34.0 \%$ \\
2007 & 588 & $83.5 \%$ & $35.4 \%$ \\
2008 & 615 & $85.4 \%$ & $35.6 \%$ \\
2009 & 591 & $82.7 \%$ & $38.2 \%$ \\
2010 & 649 & $79.7 \%$ & $41.0 \%$ \\
2011 & 723 & $81.2 \%$ & $42.3 \%$ \\
2012 & 760 & $82.2 \%$ & $48.0 \%$ \\
\hline
\end{tabular}


Table 3: Sample of performance-based vesting equity awards based on one accounting or stock performance metric: threshold, target, and ceiling performance and probability of meeting performance conditions

The table reports frequency with which firms meet performance conditions ex-post and provides comparison of this expost frequency with the simulated ex-ante probability of meeting performance conditions. The sample employed consists of 1,469 firms during the period between 1998 and 2008. The sample includes 870 firms that tie vesting of stock or stock options to stock price, accounting, or other non-financial performance metrics ("performance-based awards"). Information on performance period and hurdle rates are obtained from annual proxy statements. Stock prices and accounting measures (namely, earnings or sales) are simulated based on a bivariate normal distribution. Earnings are assumed to be normally distributed, while sales and stock prices are assumed to be log normally distributed. We simulate one million paths of the state variables for each grant. The parameters required for simulation are expected stock returns using the CAPM, returns on accounting measures, correlation between stock returns and returns on accounting measures, annual volatility in stock returns, and annual volatility in returns of accounting measures. For awards tied to accounting performance metrics, such as earnings or sales, the cumulative growth rate specified in the contract is applied over the performance period and Compustat data are used to examine whether the specified accounting targets are met ex-post when the performance period ends. For awards that are tied to stock price metrics, CRSP data are used to examine whether cumulative stock return conditions are met ex-post by the end of the performance period.

\begin{tabular}{|c|c|c|c|c|c|}
\hline & $\begin{array}{c}\text { Overall } \\
{[\mathrm{N}=4,225]}\end{array}$ & $\begin{array}{l}\text { Options } \\
{[\mathrm{N}=454]}\end{array}$ & $\begin{array}{c}\text { Restricted Stock } \\
{[\mathrm{N}=3,771]}\end{array}$ & $\begin{array}{l}\text { Accounting } \\
{[\mathrm{N}=3,093]}\end{array}$ & $\begin{array}{l}\text { Stock Price } \\
{[\mathrm{N}=1,132]}\end{array}$ \\
\hline $\begin{array}{l}\text { Performance period in years } \\
\text { (Median) }\end{array}$ & $\begin{array}{l}2.355 \\
(2.000)\end{array}$ & $\begin{array}{c}4.370 \\
(4.000)\end{array}$ & $\begin{array}{l}2.112 \\
(2.000)\end{array}$ & $\begin{array}{c}1.963 \\
(1.000)\end{array}$ & $\begin{array}{c}3.424 \\
(3.000)\end{array}$ \\
\hline $\begin{array}{l}\text { Annual threshold hurdle rate } \\
\text { (Median) }\end{array}$ & $\begin{array}{c}0.124 \\
(0.067)\end{array}$ & $\begin{array}{c}0.113 \\
(0.079)\end{array}$ & $\begin{array}{c}0.125 \\
(0.063)\end{array}$ & $\begin{array}{c}0.135 \\
(0.066)\end{array}$ & $\begin{array}{c}0.090 \\
(0.069)\end{array}$ \\
\hline $\begin{array}{l}\text { Simulated ex-ante probability of meeting } \\
\text { threshold performance }\end{array}$ & 0.442 & 0.387 & 0.449 & 0.455 & 0.407 \\
\hline $\begin{array}{l}\text { Ex-post frequency of meeting threshold } \\
\text { performance }\end{array}$ & 0.465 & 0.402 & 0.472 & 0.491 & 0.389 \\
\hline $\begin{array}{l}\text { Annual target hurdle rate } \\
\text { (Median) }\end{array}$ & $\begin{array}{c}0.155 \\
(0.096)\end{array}$ & $\begin{array}{c}0.128 \\
(0.092)\end{array}$ & $\begin{array}{c}0.158 \\
(0.097)\end{array}$ & $\begin{array}{c}0.167 \\
(0.100)\end{array}$ & $\begin{array}{c}0.116 \\
(0.087)\end{array}$ \\
\hline $\begin{array}{l}\text { Simulated ex-ante probability of meeting } \\
\text { target performance }\end{array}$ & 0.401 & 0.362 & 0.405 & 0.410 & 0.374 \\
\hline $\begin{array}{l}\text { Ex-post frequency of meeting target } \\
\text { performance }\end{array}$ & 0.411 & 0.376 & 0.415 & 0.426 & 0.368 \\
\hline $\begin{array}{l}\text { Annual maximum hurdle rate } \\
\text { (Median) }\end{array}$ & $\begin{array}{c}0.191 \\
(0.110)\end{array}$ & $\begin{array}{c}0.133 \\
(0.095)\end{array}$ & $\begin{array}{c}0.198 \\
(0.111)\end{array}$ & $\begin{array}{c}0.205 \\
(0.119)\end{array}$ & $\begin{array}{c}0.144 \\
(0.091)\end{array}$ \\
\hline $\begin{array}{l}\text { Simulated ex-ante probability of meeting } \\
\text { maximum performance }\end{array}$ & 0.362 & 0.355 & 0.363 & 0.366 & 0.350 \\
\hline $\begin{array}{l}\text { Ex-post frequency of meeting maximum } \\
\text { performance }\end{array}$ & 0.390 & 0.370 & 0.391 & 0.398 & 0.368 \\
\hline
\end{tabular}


Table 4: Simulated values of normalized stock and stock option awards with performance conditions based on one accounting or stock performance metric

The table reports simulated values of stock and stock option awards with performance conditions tied to stock price or accounting-based measures based on a current stock price of $\$ 1$. The sample used here consists of 1,469 firms during the period between 1998 and 2008. The sample includes 870 firms that tie vesting of stock or stock options to stock price, accounting, or other non-financial performance metrics ("performance-based awards"). Information on performance period, and hurdle rates are obtained from annual proxy statements. Stock prices and accounting measures (namely, earnings or sales) are simulated based on a bivariate distribution. Earnings are assumed to be normally distributed, while sales and stock prices are assumed to be log normally distributed. Simulations are run one million times. The parameters used for simulation are expected stock returns using CAPM model, beta from the CAPM, returns on accounting measures, correlation between stock returns and returns on accounting measures, annual volatility in stock returns, and annual volatility in returns of accounting measures. In case of a stock option award, the value at the end of the performance period is the ex post Black-Scholes value. In case of a stock award, the value at the end of the performance period is the simulated stock price. The simulated values of stock option and stock awards are discounted per equations (5) and (6). The normalized simulation assumes a stock price of $\$ 1$ on grant date and an exercise price of $\$ 1$ for stock options.

\begin{tabular}{cccccc}
\hline & Overall & Options & Restricted Stock & Accounting & Stock Price \\
& {$[\mathrm{N}=4,225]$} & {$[\mathrm{N}=454]$} & {$[\mathrm{N}=3,771]$} & {$[\mathrm{N}=3,093]$} & {$[\mathrm{N}=1,132]$} \\
\hline $\begin{array}{c}\text { Value without performance } \\
\text { condition (in \$) } \\
\text { (Median) }\end{array}$ & 0.951 & 0.553 & 1.000 & 0.980 & 0.874 \\
$\begin{array}{c}\text { Value with performance } \\
\text { condition(in \$) } \\
\text { (Median) }\end{array}$ & 0.593 & 0.392 & 0.618 & 0.580 & 0.629 \\
\hline
\end{tabular}


Table 5: Comparison of simulated values with company disclosed values: sub-sample of awards with performance conditions from 2006-2008 with available information on grant date fair values

The table reports simulated values of stock and stock option awards with performance conditions tied to stock price or accounting-based measures and comparison of simulated values with values disclosed by firms in annual proxy statements. The sample used here consists of 1,469 firms during the period between 1998 and 2008. The sample includes 870 firms that tie vesting of stock or stock options to stock price, accounting, or other non-financial performance metrics ("performance-based awards"). Information on performance period, and hurdle rates are obtained from annual proxy statements. Stock prices and accounting measures (namely, earnings or sales) are simulated based on a bivariate distribution. Earnings are assumed to be normally distributed, while sales and stock prices are assumed to be $\log$ normally distributed. Simulations are run one million times. The parameters used for simulation are expected stock returns using CAPM model, beta from the CAPM, returns on accounting measures, correlation between stock returns and returns on accounting measures, annual volatility in stock returns, and annual volatility in returns of accounting measures. In case of a stock option award, the value at the end of the performance period is the ex post Black-Scholes value. In case of a stock award, the value at the end of the performance period is the simulated stock price. The simulated values of stock option and stock awards are discounted per equations (5) and (6). Disclosed value is the grantdate fair value of stock or stock options disclosed in the annual proxy statements.

\begin{tabular}{|c|c|c|c|c|c|}
\hline & $\begin{array}{c}\text { Overall } \\
{[\mathrm{N}=2,835]}\end{array}$ & $\begin{array}{l}\text { Options } \\
\text { [N=197] }\end{array}$ & $\begin{array}{l}\text { Restricted Stock } \\
\qquad[\mathrm{N}=2,638]\end{array}$ & $\begin{array}{l}\text { Accounting } \\
{[\mathrm{N}=2,351]}\end{array}$ & $\begin{array}{l}\text { Stock Price } \\
{[\mathrm{N}=484]}\end{array}$ \\
\hline $\begin{array}{l}\text { Disclosed value (in \$) } \\
\text { (Median) }\end{array}$ & $\begin{array}{l}1,192,867 \\
(600,018)\end{array}$ & $\begin{array}{l}2,014,552 \\
(651,478)\end{array}$ & $\begin{array}{l}1,131,506 \\
(599,986)\end{array}$ & $\begin{array}{l}1,112,330 \\
(619,850)\end{array}$ & $\begin{array}{l}1,584,074 \\
(437,815)\end{array}$ \\
\hline $\begin{array}{l}\text { Simulated value (in \$) } \\
\text { with performance } \\
\text { condition } \\
\text { (Median) }\end{array}$ & $\begin{array}{l}1,113,264 \\
(336,628)\end{array}$ & $\begin{array}{l}2,281,206 \\
(554,826)\end{array}$ & $\begin{array}{l}1,026,045 \\
(328,393)\end{array}$ & $\begin{array}{c}934,703 \\
(313,490)\end{array}$ & $\begin{array}{l}1,980,617 \\
(594,592)\end{array}$ \\
\hline $\begin{array}{l}\text { Simulated value (in \$) } \\
\text { without performance } \\
\text { condition } \\
\text { (Median) }\end{array}$ & $\begin{array}{l}1,835,188 \\
(633,079)\end{array}$ & $\begin{array}{c}4,244,039 \\
(1,192,847)\end{array}$ & $\begin{array}{l}1,655,300 \\
(606,585)\end{array}$ & $\begin{array}{l}1,642,947 \\
(621,677)\end{array}$ & $\begin{array}{l}2,768,983 \\
(767,246)\end{array}$ \\
\hline $\begin{array}{l}p \text {-value of mean } \\
\text { difference in disclosed } \\
\text { value and simulated } \\
\text { value with p-v } \\
\text { (Median) }\end{array}$ & $\begin{array}{c}0.143 \\
(0.000)\end{array}$ & $\begin{array}{c}0.395 \\
(0.354)\end{array}$ & $\begin{array}{c}0.049 \\
(0.000)\end{array}$ & $\begin{array}{c}0.001 \\
(0.000)\end{array}$ & $\begin{array}{c}0.014 \\
(0.001)\end{array}$ \\
\hline $\begin{array}{l}p \text {-value of mean } \\
\text { difference in disclosed } \\
\text { value and simulated } \\
\text { value without } p \\
\text { (Median) }\end{array}$ & $\begin{array}{c}0.000 \\
(0.000)\end{array}$ & $\begin{array}{c}0.000 \\
(0.000)\end{array}$ & $\begin{array}{c}0.000 \\
(0.099)\end{array}$ & $\begin{array}{c}0.000 \\
(0.413)\end{array}$ & $\begin{array}{c}0.000 \\
(0.000)\end{array}$ \\
\hline
\end{tabular}


Table 6: Marginal and aggregate delta of equity-based awards with performance conditions based on a single accounting or stock performance metric

The table reports simulated deltas of stock and stock option awards with performance conditions tied to stock price or accounting-based measures. For the value-neutral grant, simulated delta with $\mathrm{p}-\mathrm{v}$ is multiplied by the ratio of value without $\mathrm{p}-\mathrm{v}$ and value with $\mathrm{p}-\mathrm{v}$ (Table 4) for each award. The sample used here consists of 1,469 firms during the period between 1998 and 2008. The sample includes 870 firms that tie vesting of stock or stock options to stock price, accounting, or other non-financial performance metrics ("performance-based awards"). Information on performance period, and hurdle rates are obtained from annual proxy statements. Stock prices and accounting measures (namely, earnings or sales) are simulated based on a bivariate distribution. Earnings are assumed to be normally distributed, while sales and stock prices are assumed to be log normally distributed. Simulations are run one million times. The parameters used for simulation are expected stock returns using CAPM model, beta from the CAPM, returns on accounting measures, correlation between stock returns and returns on accounting measures, annual volatility in stock returns, and annual volatility in returns of accounting measures. In case of a stock option award, the value at the end of the performance period is the ex post BlackScholes value. In case of a stock award, the value at the end of the performance period is the simulated stock price. The simulated values of stock option and stock awards are discounted per equations (5) and (6). Marginal stock delta (Panel A), $\boldsymbol{\delta}_{\boldsymbol{P}}$, is $\$$ change in simulated ex ante value of the p-v grant for a $1 \%$ chance in initial stock price. Marginal accounting delta (Panel B), $\boldsymbol{\delta}_{A}$, is $\$$ change in simulated ex ante value of the p-v grant for a $1 \%$ chance in the initial value of the accounting metric. Aggregate delta (Panel C), $\boldsymbol{\delta}_{A P}$, for cases in which the p-v grant schedule is contingent on an accounting performance metric, is $\$$ change in value of security for a $1 \%$ change in stock price along with a $\boldsymbol{\varepsilon}_{\boldsymbol{A P}} \%$ change in the return of accounting measure..

Panel A: Marginal stock delta, $\boldsymbol{\delta}_{S}$

\begin{tabular}{lccccc}
\hline & Overall & \multicolumn{2}{c}{ Options } & \multicolumn{2}{c}{ Restricted Stock } \\
& {$[\mathrm{N}=4,064]$} & \multicolumn{2}{c}{$[\mathrm{N}=454]$} & \multicolumn{2}{c}{$[\mathrm{N}=3,610]$} \\
\hline & & Accounting & Stock Price & Accounting & Stock Price \\
& & Metric & Metric & Metric & Metric \\
& & {$[\mathrm{N}=143]$} & {$[\mathrm{N}=311]$} & {$[\mathrm{N}=2,827]$} & {$[\mathrm{N}=783]$} \\
\hline Simulated marginal stock delta (in \$) & 35,560 & 58,756 & 62,725 & 23,146 & 65,354 \\
with p-v (Median) value neutral & $(8,554)$ & $(15,289)$ & $(23,263)$ & $(6,153)$ & $(27,110)$ \\
Simulated stock delta (in \$) & 26,722 & 58,756 & 48,076 & 23,146 & 25,300 \\
without p-v (Median) & $(7,348)$ & $(15,289)$ & $(17,209)$ & $(6,153)$ & $(8,362)$ \\
Simulated marginal stock delta (in \$) & 21,294 & 16,510 & 47,926 & 14,001 & 37,919 \\
with p-v (Median) unadjusted & $(4,876)$ & $(6,095)$ & $(17,938)$ & $(3,268)$ & $(16,335)$ \\
$p$ - value of mean difference with and & 0.000 & & 0.000 & & 0.000 \\
without p-v (Median) value neutral & $(0.000)$ & & $(0.000)$ & & $(0.000)$ \\
$p$ - value of mean difference with and & 0.000 & 0.000 & 0.880 & 0.000 & 0.000 \\
without p-v (Median) unadjusted & $(0.000)$ & $(0.000)$ & $(0.023)$ & $(0.000)$ & $(0.000)$ \\
\hline
\end{tabular}

Panel B: Marginal accounting delta, $\boldsymbol{\delta}_{A}$, for p-v grants using one accounting metric

\begin{tabular}{lccc}
\hline & $\begin{array}{c}\text { Overall } \\
{[\mathrm{N}=2,970]}\end{array}$ & $\begin{array}{c}\text { Options } \\
{[\mathrm{N}=143]}\end{array}$ & $\begin{array}{c}\text { Restricted Stock } \\
{[\mathrm{N}=2,827]}\end{array}$ \\
\hline Simulated marginal accounting delta (in \$) & 82,683 & 174,701 & 78,028 \\
with p-v (Median) value neutral & $(18,508)$ & $(43,658)$ & $(17,514)$ \\
Accounting delta (in \$) & 0 & 0 & 0 \\
without p-v (Median) & $(0)$ & $(0)$ & $(0)$ \\
Simulated marginal accounting delta (in \$) & 36,765 & 40,556 & 36,573 \\
with p-v (Median) unadjusted & $(9,234)$ & $(12,712)$ & $(9,026)$ \\
p- value of mean difference with and & 0.000 & 0.001 & 0.000 \\
without p-v (Median) value neutral & $(0.000)$ & $(0.000)$ & $(0.000)$ \\
$p$ - value of mean difference with and & 0.000 & 0.000 & 0.000 \\
without p-v (Median) unadjusted & $(0.000)$ & $(0.000)$ & $(0.000)$ \\
\hline
\end{tabular}


Panel C: Aggregate delta for involving-v awards using one accounting metric, $\boldsymbol{\delta}_{\boldsymbol{A P}}$

\begin{tabular}{lccc}
\hline & $\begin{array}{c}\text { Overall } \\
{[\mathrm{N}=2,970]}\end{array}$ & $\begin{array}{c}\text { Options } \\
{[\mathrm{N}=143]}\end{array}$ & $\begin{array}{c}\text { Restricted Stock } \\
{[\mathrm{N}=2,827]}\end{array}$ \\
\hline Simulated aggregate delta (in \$) & 43,515 & 115,981 & 39,850 \\
with p-v (Median) value neutral & $(10,412)$ & $(23,065)$ & $(10,099))$ \\
Simulated delta (in \$) & 24,861 & 58,756 & 23,146 \\
without p-v (Median) & $(6,506)$ & $(15,289)$ & $(6,153)$ \\
Simulated aggregate delta (in \$) & 22,005 & 30,378 & 21,582 \\
with p-v (Median) unadjusted & $(5,164)$ & $(8,564)$ & $(5,003)$ \\
$p$ - value of mean difference with and & 0.000 & 0.000 & 0.000 \\
without p-v (Median) value neutral & $(0.000)$ & $(0.000)$ & $(0.000)$ \\
$p$ - value of mean difference with and & 0.000 & 0.000 & 0.000 \\
without p-v (Median) unadjusted & $(0.000)$ & $(0.000)$ & $(0.001)$ \\
\hline
\end{tabular}


Table 7: Simulated vega of stock and stock options with performance conditions based on one accounting or one stock performance metric

The table reports simulated vegas of stock and stock option awards with performance conditions tied to stock price or accounting-based measures. For value-neutral analysis, simulated vega with $\mathrm{p}-\mathrm{v}$ is multiplied by the ratio of value without $\mathrm{p}-\mathrm{v}$ and value with $\mathrm{p}-\mathrm{v}$ (Table 4) for each award. The full sample consists of 1,469 firms during the period between 1998 and 2008. The sample includes 870 firms that tie vesting of stock or stock options to stock price, accounting, or other non-financial performance metrics ("performance-based awards"). Information on performance period, and hurdle rates are obtained from annual proxy statements. Stock prices and accounting measures (namely, earnings or sales) are simulated based on a bivariate normal distribution. Earnings are assumed to be normally distributed, while sales and stock prices are assumed to be log normally distributed. Simulations are run one million times. The parameters required for simulation are expected stock returns using CAPM model, returns on accounting measures, correlation between stock returns and returns on accounting measures, annual volatility in stock returns, and annual volatility in returns of accounting measures. In case of a stock option award, the value at the end of the performance period is the simulated stock price minus the exercise price, if the performance condition is met, and zero if the performance condition is not met. In case of a stock award, the value at the end of the performance period is the simulated stock price, if the performance condition is met, and zero if the performance condition is not met. The simulated values of stock option and stock awards are discounted at the expected annual stock returns. Marginal vega (Panel A) is \$ change in value of security for a 0.01 chance in stock return volatility. Aggregate vega (Panel B) for cases involving an accounting hurdle is calculated by perturbing the variance-covariance matrix of stock and accounting returns by $1.01^{2}$.

Panel A: Marginal stock return vega, $v_{P}$

\begin{tabular}{lccccc}
\hline & $\begin{array}{c}\text { Overall } \\
{[\mathrm{N}=4,064]}\end{array}$ & \multicolumn{2}{c}{ Options [N=454] } & \multicolumn{2}{c}{$\begin{array}{c}\text { Restricted Stock } \\
{[\mathrm{N}=3,610]}\end{array}$} \\
\hline & & $\begin{array}{c}\text { Accounting } \\
\text { Metric } \\
{[\mathrm{N}=143]}\end{array}$ & $\begin{array}{c}\text { Stock Price } \\
\text { Metric } \\
{[\mathrm{N}=311]}\end{array}$ & $\begin{array}{c}\text { Accounting } \\
\text { Metric } \\
{[\mathrm{N}=2,827]}\end{array}$ & $\begin{array}{c}\text { Stock Price } \\
\text { Metric } \\
{[\mathrm{N}=783]}\end{array}$ \\
\hline Simulated marginal stock return vega (in \$) & 3,496 & 12,568 & 16,995 & 0 & 9,099 \\
with p-v (Median) value neutral & $(0)$ & $(5,370)$ & $(7,445)$ & $(0)$ & $(1,428)$ \\
Simulated stock return vega (in \$) & 1,357 & 12,568 & 11,957 & 0 & 0 \\
without p-v (Median) & $(0)$ & $(5,370)$ & $(4,668)$ & $(0)$ & $(0)$ \\
Simulated marginal stock return vega (in \$) & 1,949 & 3,886 & 12,288 & 0 & 4,527 \\
with p-v (Median) unadjusted & $(0)$ & $(1,951)$ & $(4,931)$ & $(0)$ & $(891)$ \\
$p$ - value of mean difference with and & 0.000 & & 0.000 & & 0.000 \\
without p-v (Median) value neutral & $(0.000)$ & & $(0.000)$ & & $(0.000)$ \\
p- value of mean difference with and & 0.000 & 0.000 & 0.241 & & 0.000 \\
without p-v (Median) unadjusted & $(0.000)$ & $(0.000)$ & $(0.189)$ & & $(0.000)$ \\
\hline
\end{tabular}

Panel B: Marginal accounting return vega, $v_{A}$ for $p$ - $v$ grants based on a single accounting metric

\begin{tabular}{lccc} 
& $\begin{array}{c}\text { Overall } \\
{[\mathrm{N}=2,970]}\end{array}$ & $\begin{array}{c}\text { Options } \\
{[\mathrm{N}=143]}\end{array}$ & $\begin{array}{c}\text { Restricted Stock } \\
{[\mathrm{N}=2,827]}\end{array}$ \\
\hline Simulated aggregate acctg. return vega & 8,855 & 30,455 & 7,762 \\
(in \$) with p-v (Median) value neutral & $(590)$ & $(2,681)$ & $(520)$ \\
Acctg. return vega (in \$) & 0 & 0 & 0 \\
without p-v (Median) & $(0)$ & $(0)$ & $(0)$ \\
Simulated acctg. return vega (in \$) & 1,670 & 4,732 & 1,515 \\
with p-v (Median) unadjusted & $(235)$ & $(836)$ & $(211)$ \\
- value of mean difference with and & 0.000 & 0.003 & 0.000 \\
without p-v (Median) value neutral & $(0.000)$ & $(0.156)$ & $(0.000)$ \\
$p$ - value of mean difference with and & 0.000 & 0.000 & 0.000 \\
without p-v (Median) unadjusted & $(0.000)$ & $(0.000)$ & $(0.000)$ \\
\hline
\end{tabular}


Panel C: Aggregate vega for $p$-v grants based on a single accounting metric, $v_{\text {Agg }}$

\begin{tabular}{lccc}
\hline & $\begin{array}{c}\text { Overall } \\
{[\mathrm{N}=2,970]}\end{array}$ & $\begin{array}{c}\text { Options } \\
{[\mathrm{N}=143]}\end{array}$ & $\begin{array}{c}\text { Restricted Stock } \\
{[\mathrm{N}=2,827]}\end{array}$ \\
\hline Simulated aggregate vega (in \$) & 13,126 & 52,086 & 11,155 \\
with p-v (Median) value neutral & $(1,130)$ & $(9,742)$ & $(976)$ \\
Simulated vega (in \$) & 605 & 12,568 & 0 \\
without p-v (Median) & $(0)$ & $(5,370)$ & $(0)$ \\
Simulated aggregate vega (in \$) & 3,474 & 10,741 & 3,107 \\
with p-v (Median) unadjusted & $(476)$ & $(3,110)$ & $(417)$ \\
p- value of mean difference with and & 0.000 & 0.000 & 0.000 \\
without p-v (Median) value neutral & $(0.000)$ & $(0.000)$ & $(0.000)$ \\
$p$ - value of mean difference with and & 0.000 & 0.030 & 0.000 \\
without p-v (Median) unadjusted & $(0.000)$ & $(0.000)$ & $(0.000)$ \\
\hline
\end{tabular}


Table 8: Simulated value, delta and vega of stock and stock options with double performance conditions for six sample contracts

The table reports simulated value, delta, and vega of stock and stock option awards with double performance conditions tied to stock price and accounting-based measures. Panel A reports mean numbers for three representative "min" cases involving an "AND" condition (see Section 3.1). Panel B reports mean numbers for three representative "max" cases involving an "OR" condition. Both panels contain in column 1 a benchmark grant absent the p-v provision (so ex post value of the options or stock times target number of units). Column 3 in Panel A contains an additional hypothetical comparison grant made up of two side-by-side grants, each based on the analogous single-metric grant schedule, for each of the stock and accounting metrics, that would obtain in the absence of the other performance metric. The assumed allocation of this more flexible grant is $50 \%$ of target units to each side-by-side grant schedule. Details on delta and vega are as outlined in Tables 6 and 7 . In all cases, payout is determined by the achievement of both accounting and stock price conditions at the threshold, target and maximum levels.

Panel A: Three cases involving an "AND" condition

\begin{tabular}{cccc}
\hline & $\begin{array}{c}\text { No P-V } \\
\text { Provision }\end{array}$ & $\begin{array}{c}\text { "Min" P-V } \\
\text { Provision }\end{array}$ & $\begin{array}{c}\text { Hypothetical "Side-by- } \\
\text { Side” P-V Provision }\end{array}$ \\
\hline $\begin{array}{c}\text { Simulated value (in \$) } \\
\text { (Median) }\end{array}$ & $2,022,512$ & 577,867 & $1,291,153$ \\
$(1,377,915)$ & $(649,976)$ & $(1,263,932)$ \\
Simulated marginal stock delta & 30,038 & 29,409 & 42,278 \\
(in \$) & $(13,779)$ & $(18,500)$ & $(23,326)$ \\
(Median) & & & \\
Simulated marginal stock return & 4,237 & 9,066 & 9,622 \\
$\quad \begin{array}{c}\text { vega (in \$) } \\
\text { (Median) }\end{array}$ & $(0)$ & $(1,290)$ & $(3,088)$ \\
Simulated aggregate delta (in \$) & & & \\
(Median) & & 33,275 & 56,111 \\
Simulated aggregate vega (in \$) & & $(24,872)$ & $(25,699)$ \\
(Median) & & & 11,479 \\
\end{tabular}

Panel B: Three cases involving an "OR" condition

\begin{tabular}{ccc}
\hline & $\begin{array}{c}\text { No P-V } \\
\text { Provision }\end{array}$ & $\begin{array}{c}\text { "Max" P-V } \\
\text { Provision }\end{array}$ \\
\hline $\begin{array}{c}\text { Simulated value (in \$) } \\
\text { (Median) }\end{array}$ & $3,607,341$ & $3,455,200$ \\
$(755,525)$ & $(721,392)$ \\
Simulated marginal stock delta & 37,189 & 52,952 \\
(in \$) & $(10,904)$ & $(18,229)$ \\
(Median) & & \\
Simulated marginal stock return & 1,163 & 17,959 \\
vega (in \$) & $(0)$ & $(5,024)$ \\
(Median) & & \\
& & 62,078 \\
Simulated aggregate delta (in \$) & & $(20,022)$ \\
(Median) & & 35,983 \\
Simulated aggregate vega (in \$) & & $(7,491)$ \\
(Median)
\end{tabular}


Table 9: Summary statistics

The table reports summary statistics for firm-years with and without a performance-based vesting (p-v) provision. The full sample consists of 1,833 firms during the period between 1998 and 2012. The sample includes 1,268 firms that tie vesting of stock or stock options to stock price, accounting, or other non-financial performance metrics ("performancebased awards") and 1,793 firms that tie vesting of stock or stock options to passage of time ("time-based awards"). New CEO is an indicator variable that takes the value 1 if the CEO was appointed to the company in the year (or the previous year) of the grant, and 0 otherwise. Business segments is the total number of business segments obtained from the Compustat industry segment file. Volatility is defined as the standard deviation of daily stock return. Investments is the sum of R\&D, advertising and capital expenditures. Industry-adjusted stock return is defined as annual stock return minus the median stock returns for firms in the same two-digit SIC code. Market cap is stock price multiplied by total common shares outstanding. Industry adoption is the percentage of firms in the same two-digit SIC code that have any p-v provisions in equity awards. Post 2005 is an indicator variable that takes the value one if the year is 2006 or later, and zero otherwise. CEO ownership is defined as the aggregate number of shares owned (including exercisable stock options) by the CEO divided by total number of shares outstanding. 5\% inst. ownership is aggregate ownership by institutions owning at least $5 \%$ of the firm's common stock. Data on institutional ownership are obtained from 13F filings made available by Thomson Reuters. Outside directors is the proportion of outside directors on the board. Board size in number of directors sitting on the board. Data on directors are obtained from IRRC. CEO Chair is an indicator variable that takes the value 1 if the CEO is also the chairman of the company in the fiscal year prior to the grant, and 0 otherwise. Director interlock is the proportion of directors of a firm that share common directorships with firms that use any type of p-v provisions in equity awards. The Student's $t$-test (Wilcoxon rank-sum test) is used to test whether there is a statistically significant difference between the means (medians). ${ }^{* * *}, * *$, and ${ }^{*}$ denote significance at less than $1 \%$, $5 \%$, and $10 \%$ levels, two-tailed tests, respectively.

\begin{tabular}{|c|c|c|c|c|c|c|}
\hline & \multicolumn{2}{|c|}{$\begin{array}{c}\text { P-V firm-years } \\
{[\mathrm{N}=6,959]}\end{array}$} & \multicolumn{2}{|c|}{$\begin{array}{c}\text { Non P-V firm-years } \\
\qquad \mathrm{N}=12,570]\end{array}$} & \multirow{2}{*}{\begin{tabular}{|l}
$t$-stat \\
(Means)
\end{tabular}} & \multirow{2}{*}{$\begin{array}{l}\text { Wilcoxon } 2 \\
\text { (Medians) }\end{array}$} \\
\hline New CEO & $\begin{array}{c}\text { Mean } \\
0.250\end{array}$ & $\begin{array}{c}\text { Median } \\
0.000\end{array}$ & $\begin{array}{c}\text { Mean } \\
0.222\end{array}$ & $\begin{array}{c}\text { Median } \\
0.000\end{array}$ & & \\
\hline Business segments & 2.648 & 2.000 & 2.219 & 1.000 & $14.51^{* * *}$ & $16.87 * * *$ \\
\hline Volatility & 0.024 & 0.020 & 0.029 & 0.025 & $25.07 * * *$ & $24.11 * * *$ \\
\hline Investment/Assets & 0.075 & 0.059 & 0.096 & 0.069 & $14.77 * * *$ & $8.50 * * *$ \\
\hline Industry-adj. stock return & 0.115 & 0.047 & 0.210 & 0.064 & $8.86 * * *$ & $4.78^{* * *}$ \\
\hline Market cap (in \$ million) & 12,911 & 4,176 & 8,805 & 2,459 & $9.39 * * *$ & $28.65^{* * *}$ \\
\hline Industry adoption & 0.442 & 0.461 & 0.273 & 0.226 & $57.25 * * *$ & $53.73 * * *$ \\
\hline Post 2005 & 0.656 & 1.000 & 0.317 & 0.000 & $48.19 * * *$ & $45.79 * * *$ \\
\hline CEO ownership & 0.020 & 0.006 & 0.044 & 0.012 & $18.10^{* * *}$ & $25.21 * * *$ \\
\hline $5 \%$ inst. ownership & 0.162 & 0.138 & 0.151 & 0.127 & $5.02 * * *$ & $6.04^{* * *}$ \\
\hline Outside directors & 0.767 & 0.800 & 0.686 & 0.714 & $27.33^{* * *}$ & $25.62 * * *$ \\
\hline Board size & 11.726 & 11.000 & 10.369 & 10.000 & $16.26^{* * *}$ & $18.48^{* * *}$ \\
\hline CEO Chair & 0.657 & 1.000 & 0.632 & 1.000 & $2.57 * * *$ & $2.56^{* * *}$ \\
\hline Director interlock & 0.207 & 0.181 & 0.131 & 0.909 & $20.95 * * *$ & $23.58 * * *$ \\
\hline
\end{tabular}




\section{Table 10: Determinants of performance-vesting}

This table provides maximum likelihood estimates from a logistic regression of use of performance-vesting stock and stock options over 1998-2012. The dependent variable takes the value one if the firm granted stock or stock options with p-v provisions, and zero otherwise. The sample of $\mathrm{p}-\mathrm{v}$ firms is explained in Table 1, and all explanatory variables are as explained in Table 9. The specifications based on data on compensation consultants cover 2006-2012. Use comp consult is an indicator variable set to one if a firm uses a compensation consultant, and zero otherwise. Big comp consult is an indicator variables set to one if a firm uses a large compensation consultant, defined as a compensation consultant that ranks in the top seven by market share, and zero otherwise. All models include 2-digit SIC code fixed effects. Absolute values of $Z$-statistics are reported in parentheses. Standard errors are corrected for heteroskedasticity and clustering at the firm level. $* * *, * *$, and $*$ denote significance at less than $1 \%, 5 \%$, and $10 \%$ levels, two-tailed tests, respectively.

\begin{tabular}{|c|c|c|c|c|c|c|}
\hline & (1) & (2) & (3) & (4) & (5) & (6) \\
\hline Intercept & $\begin{array}{c}-1.510 * * * \\
(-4.79)\end{array}$ & $\begin{array}{c}-1.430 * * * \\
(-3.83)\end{array}$ & $\begin{array}{c}-1.515^{* * *} \\
(-3.10)\end{array}$ & $\begin{array}{c}13.047 * * * \\
(16.78)\end{array}$ & $\begin{array}{c}14.266^{* * *} \\
(22.00)\end{array}$ & $\begin{array}{c}14.577 * * * \\
(22.32)\end{array}$ \\
\hline New CEO & $\begin{array}{c}0.130 * * \\
(2.50)\end{array}$ & $\begin{array}{c}0.126 * * \\
(2.15)\end{array}$ & $\begin{array}{c}0.200 * * * \\
(2.94)\end{array}$ & $\begin{array}{l}0.002 \\
(0.03)\end{array}$ & $\begin{array}{l}-0.070 \\
(-0.72)\end{array}$ & $\begin{array}{l}0.061 \\
(0.52)\end{array}$ \\
\hline Business segments & $\begin{array}{c}0.062 * * * \\
(3.12)\end{array}$ & $\begin{array}{c}0.071^{* * *} \\
(3.35)\end{array}$ & $\begin{array}{c}0.061^{* * * *} \\
(2.72)\end{array}$ & $\begin{array}{l}0.047^{*} \\
(1.69)\end{array}$ & $\begin{array}{c}0.067 * * \\
(1.98)\end{array}$ & $\begin{array}{l}0.058 \\
(1.44)\end{array}$ \\
\hline Volatility & $\begin{array}{c}-13.612 * * * \\
(-6.95)\end{array}$ & $\begin{array}{c}-14.297 * * * \\
(-6.32)\end{array}$ & $\begin{array}{c}-20.589 * * * \\
(-6.38)\end{array}$ & $\begin{array}{c}-8.457 * * * \\
(-3.79)\end{array}$ & $\begin{array}{c}-5.778 * * \\
(-2.14)\end{array}$ & $\begin{array}{l}-7.489 \\
(-1.58)\end{array}$ \\
\hline Investment/Assets & $\begin{array}{c}-2.032 * * * \\
(-3.74)\end{array}$ & $\begin{array}{c}-2.165^{* * *} \\
(-3.38)\end{array}$ & $\begin{array}{l}-0.855 \\
(-1.06)\end{array}$ & $\begin{array}{c}-2.257 * * * \\
(-3.26)\end{array}$ & $\begin{array}{c}-2.643^{* * *} \\
(-2.98)\end{array}$ & $\begin{array}{l}-1.529 \\
(-1.36)\end{array}$ \\
\hline Industry-adj. stock return & $\begin{array}{c}-0.136 * * \\
(-2.46)\end{array}$ & $\begin{array}{c}-0.129 * * \\
(-2.54)\end{array}$ & $\begin{array}{l}-0.077 \\
(-1.33)\end{array}$ & $\begin{array}{l}-0.046 \\
(-0.61)\end{array}$ & $\begin{array}{l}-0.050 \\
(-0.72)\end{array}$ & $\begin{array}{l}0.075 \\
(0.64)\end{array}$ \\
\hline Log of market cap & $\begin{array}{c}0.183^{* * *} \\
(6.08)\end{array}$ & $\begin{array}{c}0.168^{* * *} \\
(4.94)\end{array}$ & $\begin{array}{l}0.032 \\
(0.73)\end{array}$ & $\begin{array}{c}0.165^{* * *} \\
(4.05)\end{array}$ & $\begin{array}{c}0.151^{* * *} \\
(3.14)\end{array}$ & $\begin{array}{l}-0.001 \\
(-0.02)\end{array}$ \\
\hline Industry adoption & $\begin{array}{c}3.026 * * * \\
(16.56)\end{array}$ & $\begin{array}{c}2.634^{* * *} \\
(11.89)\end{array}$ & $\begin{array}{c}2.125^{* * *} \\
(7.68)\end{array}$ & $\begin{array}{c}2.640 * * * \\
(11.89)\end{array}$ & $\begin{array}{c}1.540 * * * \\
(5.09)\end{array}$ & $\begin{array}{c}0.928 * * \\
(2.32)\end{array}$ \\
\hline Post 2005 & $\begin{array}{c}0.587 * * * \\
(8.30)\end{array}$ & $\begin{array}{c}0.603^{* * *} \\
(7.94)\end{array}$ & $\begin{array}{c}0.582 * * * \\
(6.23)\end{array}$ & & & \\
\hline CEO ownership & & $\begin{array}{c}-3.666 * * * \\
(-3.96)\end{array}$ & $\begin{array}{c}-2.556^{*} \\
(-1.80)\end{array}$ & & $\begin{array}{c}-2.544 * * \\
(-2.12)\end{array}$ & $\begin{array}{c}-3.008 * * \\
(-1.98)\end{array}$ \\
\hline 5\% inst. ownership & & $\begin{array}{l}0.490^{*} \\
(1.77)\end{array}$ & $\begin{array}{l}0.033 \\
(0.10)\end{array}$ & & $\begin{array}{c}0.725 * * \\
(2.17)\end{array}$ & $\begin{array}{l}0.325 \\
(0.66)\end{array}$ \\
\hline Outside directors & & & $\begin{array}{c}1.612^{* * *} \\
(4.85)\end{array}$ & & & $\begin{array}{c}1.669 * * * \\
(3.29)\end{array}$ \\
\hline Board size & & & $\begin{array}{c}0.027 * * * \\
(2.70)\end{array}$ & & & $\begin{array}{l}0.005 \\
(0.43)\end{array}$ \\
\hline CEO Chair & & & $\begin{array}{l}0.119 \\
(1.40)\end{array}$ & & & $\begin{array}{l}-0.008 \\
(-0.06)\end{array}$ \\
\hline Director interlock & & & $\begin{array}{c}1.354^{* * *} \\
(6.40)\end{array}$ & & & $\begin{array}{c}1.384^{* * *} \\
(3.60)\end{array}$ \\
\hline Use comp consult & & & & $\begin{array}{c}0.977 * * * \\
(5.89)\end{array}$ & $\begin{array}{c}0.651^{* * *} \\
(3.31)\end{array}$ & $\begin{array}{c}0.563^{* *} \\
(2.21)\end{array}$ \\
\hline Big comp consult & & & & $\begin{array}{c}0.222 * * \\
(2.43)\end{array}$ & $\begin{array}{c}0.429 * * * \\
(3.42)\end{array}$ & $\begin{array}{c}0.450 * * * \\
(2.89)\end{array}$ \\
\hline Pseudo R-square & 0.166 & 0.155 & 0.165 & 0.095 & 0.098 & 0.111 \\
\hline $\mathrm{N}$ & 15,653 & 12,186 & 8,681 & 7,022 & 3,990 & 2,710 \\
\hline
\end{tabular}


Table 11: Determinants of usage of accounting metrics in performance-vesting provisions

This table provides maximum likelihood estimates from a logistic regression of use of accounting measures in performancevesting stock and stock options. The dependent variable takes the value one if the firm granted stock or stock options with p$\mathrm{v}$ provisions that contain accounting measures, and zero if the firm did no use any $\mathrm{p}-\mathrm{v}$ provisions. The sample of $\mathrm{p}-\mathrm{v}$ firms is explained in Table 1, and all explanatory variables are as explained in Table 9. Ratio of volatility of noise and correlation in noise are defined using methodology developed in Sloan (1993). All models include 2-digit SIC code fixed effects. Absolute values of Z-statistics are reported in parentheses. Standard errors are corrected for heteroskedasticity and clustering at the firm level. ${ }^{* * *}, * *$, and ${ }^{*}$ denote significance at less than $1 \%, 5 \%$, and $10 \%$ levels, two-tailed tests, respectively.

\begin{tabular}{|c|c|c|c|}
\hline & (1) & (2) & (3) \\
\hline \multirow[t]{2}{*}{ Intercept } & $16.669 * * *$ & $17.577 * * *$ & $17.095 * * *$ \\
\hline & $(14.80)$ & (16.25) & (33.13) \\
\hline \multirow[t]{2}{*}{ New CEO } & 0.068 & 0.105 & $0.190 * *$ \\
\hline & $(1.12)$ & (1.54) & (2.44) \\
\hline \multirow[t]{2}{*}{ Business segments } & $0.071^{* * *}$ & $0.078 * * *$ & $0.075^{* * *}$ \\
\hline & (3.03) & (3.08) & (2.79) \\
\hline \multirow[t]{2}{*}{ Volatility } & $-16.988 * * *$ & $-18.097 * * *$ & $-26.858 * * *$ \\
\hline & $(-6.78)$ & $(-6.43)$ & $(-6.82)$ \\
\hline \multirow[t]{2}{*}{ Investment/Assets } & $-2.133 * * *$ & $-2.267 * * *$ & -0.760 \\
\hline & $(-3.12)$ & $(-2.92)$ & $(-0.82)$ \\
\hline \multirow[t]{2}{*}{ Industry-adj. return on assets } & $-0.408^{*}$ & -0.313 & -0.444 \\
\hline & $(-1.76)$ & $(-1.25)$ & $(-1.50)$ \\
\hline \multirow[t]{2}{*}{ Log of market cap } & $0.201 * * *$ & $0.179 * * *$ & 0.016 \\
\hline & (5.63) & $(4.42)$ & $(0.31)$ \\
\hline \multirow[t]{2}{*}{ Industry adoption } & $3.005^{* * *}$ & $2.515^{* * *}$ & $1.869 * * *$ \\
\hline & (14.48) & (9.68) & (5.93) \\
\hline \multirow[t]{2}{*}{ Post 2005} & $0.875^{* * *}$ & $0.919 * * *$ & $0.918^{* * *}$ \\
\hline & (10.91) & $(10.50)$ & $(8.72)$ \\
\hline \multirow[t]{2}{*}{ CEO ownership } & & $-3.684^{* * *}$ & $-2.532 *$ \\
\hline & & $(-3.68)$ & $(-1.75)$ \\
\hline \multirow[t]{2}{*}{ 5\% inst. ownership } & & 0.408 & -0.029 \\
\hline & & $(1.21)$ & $(-0.07)$ \\
\hline \multirow[t]{2}{*}{ Outside directors } & & & $2.016^{* * *}$ \\
\hline & & & $(5.37)$ \\
\hline \multirow[t]{2}{*}{ Board size } & & & $0.035 * * *$ \\
\hline & & & $(3.25)$ \\
\hline \multirow[t]{2}{*}{ CEO Chair } & & & 0.130 \\
\hline & & & $(1.39)$ \\
\hline \multirow[t]{2}{*}{ Director interlock } & & & $1.467 * * *$ \\
\hline & & & $(5.83)$ \\
\hline \multirow[t]{2}{*}{ Ratio of Vol. of Noise } & -0.005 & -0.011 & -0.016 \\
\hline & $(-0.42)$ & $(-0.57)$ & $(-0.70)$ \\
\hline \multirow[t]{2}{*}{ Correlation in Noise } & $-0.268^{* *}$ & $-0.331^{* * *}$ & $-0.297 *$ \\
\hline & $(-2.56)$ & $(-2.76)$ & $(-1.93)$ \\
\hline Pseudo R-square & 0.195 & 0.178 & 0.198 \\
\hline $\mathrm{N}$ & 13,037 & 10,173 & 7,444 \\
\hline
\end{tabular}


Table 12: Financial and investment policies, and firm performance surrounding use of performance-vesting

This table provides details of financial and investment policy, and firm performance surrounding the use of performancevesting provisions in stock and stock option grants. The sample of $\mathrm{p}-\mathrm{v}$ firms is explained in Table 1. Control firms are selected by matching with p-v firms by size (measured by market value of equity), and industry (defined as 2-digit SIC code). A regression of the financial and investment policy measures, and firm performance is run on: PV, Post and PV*Post. PV takes the value one if the firm uses p-v provisions, and zero otherwise. Post takes the value one if the year follows the fiscal year of the grant of $\mathrm{p}-\mathrm{v}$ awards (Years $+1,+2,+3$ ), and zero if the year precedes the p-v grant (Year -1 ). Year 0 is the fiscal year of grant of $\mathrm{p}-\mathrm{v}$ awards. Leverage is total long-term debt divided by book value of total assets. Investments is the sum of R\&D, advertising and capital expenditures. Annual volatility is defined as the annualized standard deviation of daily stock return. Return on assets is income before extraordinary items divided by book value of total assets. Standard errors are corrected for heteroskedasticity and clustering at the firm level.

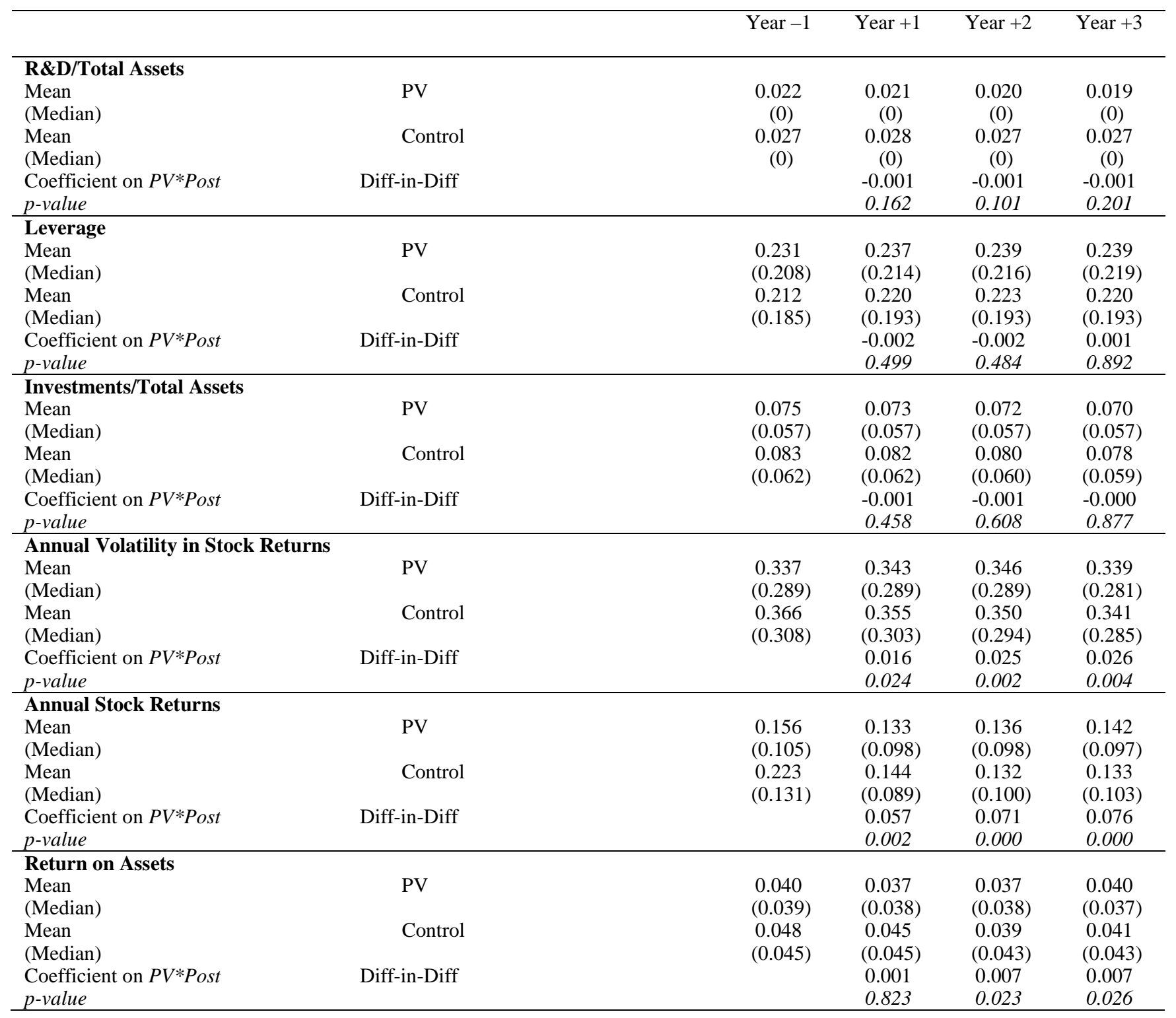

